Article

\title{
Analysis of Electric Power Quantities of Road LED Luminaires under Sinusoidal and Non-Sinusoidal Conditions
}

\author{
Roman Sikora *(D) and Przemysław Markiewicz \\ Institute of Electrical Power Engineering, Lodz University of Technology, 90-924 Lodz, Poland; \\ przemyslaw.markiewicz@p.lodz.pl \\ * Correspondence: roman.sikora@p.lodz.pl; Tel.: +48-42-631-25-95
}

Received: 13 February 2019; Accepted: 18 March 2019; Published: 21 March 2019

check for updates

\begin{abstract}
The paper presents the results of laboratory tests concerning the measurements of electrical parameters of road lighting luminaires. These measurements were focused on determining the dependence of the electrical parameters of the luminaires versus the changes of the RMS (Root Mean Square) value of the supply voltage and the level of disturbances in the supply voltage. The basic electrical parameters for light-emitting diode (LED) luminaires were analysed with the option of luminous flux adjustment if it existed. During the laboratory measurements, the luminaires were powered from the Agilent 6834B distorted voltage generator within the assumed acceptable range of the changes in the deformation level resulting from the applicable legal provisions for the reproduction of actual power supply conditions.
\end{abstract}

Keywords: road LED luminaires; electric power quantities; harmonics

\section{Introduction}

Street lighting is one of the most important public services. It provides an appropriate level of road safety and security in public spaces. It improves the comfort of community life and is one of the factors influencing the economic development of the given area. Community members expect that the public service provider ensures a high quality of road lighting. On the other hand, the supplier is interested in providing the service with the required quality parameters at the lowest possible financial outlay. In addition, the energy policy of the European Union encourages the use of energy-saving solutions using legal instruments [1]. A measure of the quality of a road lighting service is to provide the appropriate lighting parameters on the road in accordance with the multi-sheet standard EN 13201 [1]. The social acceptance of the technical solutions used is also very important. For example, the use of light sources of different colour temperature is required from this point of view. Installation of road lighting is a receiver of electricity of considerable power, although the unit power of lighting luminaires is small. The number of lighting points determines the participation in the overall power balance. The administrator of the lighting installation, bearing the costs of its use, is interested in maximum reduction of these costs. This can be accomplished by the use of modern lighting luminaires with adjustable power. They can be a luminaire, made in any technology, but equipped with appropriate power and regulation systems. The regulation is implemented via central SCADA (Supervisory Control and Data Acquisition) systems or by autonomous intelligent lighting luminaires. With the SCADA system, a group of luminaires as well as a single point of light can be controlled. Standard [1] allows for the possibility to lower the lighting class of the road due to reduction of road traffic. Lowering the lighting class of the road has an impact on reduction of the requirements of the lighting parameters of the road (e.g., luminance or illuminance) which is realized by reducing the power of the luminaires. 
It should be remembered that the main aim of road lighting is to ensure road safety. Reduction of electricity consumption cannot be achieved at the expense of deterioration of lighting requirements.

The correct operation of any electrical device supplied from the grid depends, among other things, on the quality of the supply voltage. The problems associated with appropriate parameters of supply voltage are described in many publications [2-12]. The quality parameters of the supply voltage are specified in the European standard EN 50160 [13].

The supplier of electricity and the recipient are both responsible for ensuring the appropriate quality of the supply voltage. Another very important reason for the widespread interest in the quality of electricity is the increasing saturation of power grids with non-linear loads, which are the main sources of disturbances occurring in power grids in the form of current higher harmonics. In lighting grids the problem of generating the disturbances into the power grid appears when replacing incandescent light sources with discharge sources. The basic elements of the luminaire for gas discharge lamps are light sources, magnetic or electronic ballasts, and for magnetic ballasts the ignition systems. Lamps applied for lighting purposes operate on the principle of radiation emission caused by the flow of electric current through a gas diluted at low or high pressure. Physical phenomena occurring during operation of gas-discharge light sources cause these receivers to have non-linear current-voltage characteristics. An additional element of the lighting luminaire used to compensate the inductive reactive power is the capacitor. A properly selected capacitor allows for improving the power factor of the luminaire, but it can be the cause of the increase in disturbances generated to the mains $[8,9,12]$. Higher harmonics of currents and voltages adversely have an influence on the work of the transformer [14] and cause additional losses for three-phase systems in the neutral conductor [15]. The application of light-emitting diode (LED) technology in lighting has forced the use of electronic ballasts in luminaires. The electronic ballast is built as a power electronic system whose current-voltage characteristics are non-linear. It is usually equipped with an input EMC (electromagnetic compatibility) filter and a PFC (power factor correction) system. Both of them limit the negative impact on the power supply network (reduce the level of disturbances generated to the mains) and improve the power factor [16,17]. Comparing the effect of luminaires on the power supply network with high-pressure sodium lamps equipped with magnetic ballasts and electronic equipment it can be established as shown in the studies $[11,18]$ that the electronic ballast usually has a higher power factor and a lower coefficient of $T H D_{I}$ current.

LED luminaires consist of a LED matrix and an impulse power supply (AC/DC). Due to the design and operation principle of the switching power supply (SMPS), the LED luminaire is a non-linear receiver that can negatively affect the supply network $[8,9,12,18,19]$. Luminaires are classified as Class C receivers in accordance with EN 61000-3-2: 2014 Standard [20]. Luminaires as other products approved for trade, undergo EMC tests as described in [20]. The level of disturbances generated to the mains network is verified here.

It is important from the operational point of view how the deformation of the supply voltage affects the work of a lighting luminaire. Significant indicators responsible for the correct operation of the luminaire include, among others, the RMS (Root Mean Square) value of the supply voltage and the $T H D_{V}$ (Total Harmonic Distortion of the voltage waves) factor. The $T H D_{V}$ factor of the supply voltage including harmonics up to the order of 40 should not exceed $8 \%$. In practice, due to the small installed capacities, lighting switchboards are supplied from transformer stations supplying other consumers such as: residential premises, commercial buildings or small industrial plants. The quality of the supply voltage is influenced by the daily power profile consumed by other receipts and the share of the ever-increasing number of receivers with non-linear characteristics. Road lighting installations work at night. The transformer is usually loaded to a lesser extent than during daylight hours, which makes the value of $T H D_{V}$ coefficient less than during the day.

The paper will present the results of laboratory tests of typical road lighting luminaires made in LED technology supplied with distorted voltage with $T H D_{V}$ coefficient values not exceeding the permissible value for low-voltage networks. In the literature [10,21-24], this issue has not been 
comprehensively described. In addition, there are a number of publications presenting the results of the measurements and simulations concerning the emission of higher harmonics by lighting luminaires. In general, the studies have been performed with sinusoidal voltage power supply (non-deformed). In the actual power grid, the voltage is always deformed. Therefore, it is important how the level of higher harmonics occurring in the supply voltage affects the electrical parameters of the lighting luminaires and what the influence of the level of control is, as discussed here.

\section{Methods of Measurement Performance}

\subsection{Definition of Electric Power Quantities According to IEEE 1457}

According to the guidelines contained in [25] for the steady state and the occurrence of non-sinusoidal currents and voltages, the RMS values of voltage $V$ and current $I$ have two components:

$$
\begin{gathered}
V^{2}=V_{0}^{2}+V_{H}^{2} \\
I^{2}=I_{0}^{2}+I_{H}^{2}
\end{gathered}
$$

The component with the lower index 0 means a constant component. For the remaining components, the index is the number of the actual harmonic of the current or voltage.

$$
\begin{gathered}
V_{H}^{2}=V_{0}^{2}+\sum_{H \neq 1} V_{H}^{2}=V^{2}-V_{1}^{2} \\
I_{H}^{2}=I_{0}^{2}+\sum_{H \neq 1} I_{H}^{2}=I^{2}-I_{1}^{2}
\end{gathered}
$$

Current and voltage measure of the distorted deformation of the higher harmonic voltage or current coefficients are respectively $T H D_{V}$ and $T H D_{I}$ defined as:

$$
\begin{aligned}
T H D_{V} & =\frac{V_{H}}{V_{1}}=\sqrt{\left(\frac{V}{V_{1}}\right)^{2}-1} \\
\operatorname{THD}_{I} & =\frac{I_{H}}{I_{1}}=\sqrt{\left(\frac{I}{I_{1}}\right)^{2}-1}
\end{aligned}
$$

With such assumptions, the active power of the $P$ receiver also has two components: $P_{1}$ associated with the voltage and current of the fundamental harmonic and $P_{H}$ associated with harmonics of the order different from unity.

$$
P=P_{1}+P_{H}
$$

The components contained in Equation (7) are defined as:

$$
\begin{gathered}
P_{1}=V_{1} \cdot I_{1} \cdot \cos \varphi_{1} \\
P_{H}=V_{0} \cdot I_{0}+\sum_{H \neq 1} V_{H} \cdot I_{H} \cdot \cos \varphi_{H}
\end{gathered}
$$

The power factor $P F_{1}\left(\cos \varphi_{1}\right)$ for the fundamental harmonic is the ratio of the active power $P_{1}$ to the apparent power $S_{1}$ for the fundamental harmonic (10).

$$
P F_{1}=\cos \varphi_{1}=\frac{P_{1}}{S_{1}}
$$

Apparent power for the fundamental harmonic $S_{1}$ is calculated from dependence (11) or (12).

$$
S_{1}=V_{1} \cdot I_{1}
$$




$$
S_{1}^{2}=P_{1}^{2}+Q_{1}^{2}
$$

In the general case for non-sinusoidal voltages and currents, the power factor $P F$ is the ratio of the total active power $P$ to the total apparent power $S$.

$$
P F=\frac{P}{S}
$$

In the total apparent power, there is a component associated with the fundamental harmonic $S_{1}$ and other harmonics together with the constant component $S_{H}$.

$$
S^{2}=S_{1}^{2}+S_{H}^{2}
$$

The standard [19] introduces the notion of nonfundamental apparent power of $S_{N}$ defined as:

$$
S_{N}^{2}=D_{I}^{2}+D_{V}^{2}+S_{H}^{2}
$$

where, respectively

$$
D_{I}=V_{1} \cdot I_{H}
$$

and

$$
D_{V}=V_{H} \cdot I_{1}
$$

In the case when $T H D_{V}<T H D_{I} S_{H}$ can be determined from the following relationship:

$$
S_{H}=S_{1} \sqrt{T H D_{I}^{2}+T H D_{V}^{2}}
$$

The power factor $P F$ can be determined from the dependence (19) after transformation the dependence (13)

$$
P F=\frac{P}{S}=\frac{P_{1}+P_{H}}{\sqrt{S_{1}^{2}+S_{H}^{2}}}=\frac{\left(\frac{P_{1}}{S_{1}}\right) \cdot\left[1+\left(\frac{P_{H}}{P_{1}}\right)\right]}{\sqrt{1+\left(\frac{S_{H}}{S_{1}}\right)^{2}}}=\frac{\left[1+\left(\frac{P_{H}}{P_{1}}\right)\right] \cdot P F_{1}}{\sqrt{1+T H D_{I}^{2}+T H D_{V}^{2}+\left(T H D_{I} \cdot T H D_{V}\right)^{2}}}
$$

When the supply voltage is purely sinusoidal, so when $T H D_{V}=0 \%$, then the power factor $P F$ described by the dependence (19), after its simplification, can be determined according to the dependence (20).

$$
P F==\frac{P F_{1}}{\sqrt{1+T H D_{I}^{2}}}
$$

\subsection{Method of Measurements Electrical Parameters of Road Light-Emitting Diode (LED) Luminaires}

The purpose of measurements is to estimate the impact of road lighting luminaires on the electrical parameters such as:

- changes of supply voltage RMS value;

- distortion level of supply voltage;

- dimming.

Measurements to estimate the impact of the RMS value of the supply voltage were made using the measuring system shown in Figure 1a. The measuring system consisted of the Agilent 6834B and the FLUKE 1760 power quality analyser. Using the AC Agilent 6834B power supply, the tested luminaires were supplied with sinusoidal voltage of adjustable RMS value in the range of $230 \pm 10 \%$, that is from $207 \mathrm{~V}$ to $253 \mathrm{~V}$. 
Measurements of electrical parameters of luminaires supplied with distorted voltage were also made using the measuring system shown in Figure 1a. In order to measure previously prepared voltage signals the Agilent 6834B power supply was used. The measurements were performed for the below-mentioned voltages with a given value of THD voltage:

- $T H D_{V}=0 \%$ (supply with sinusoidal voltage);

- $T H D_{V}=1.79 \%$;

- $T H D_{V}=2.5 \%$;

- $T H D_{V}=5.0 \%$;

- $T H D_{V}=7.5 \%$.

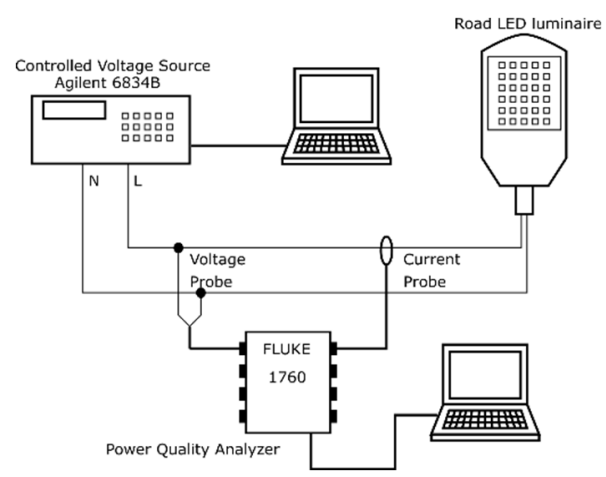

(a)

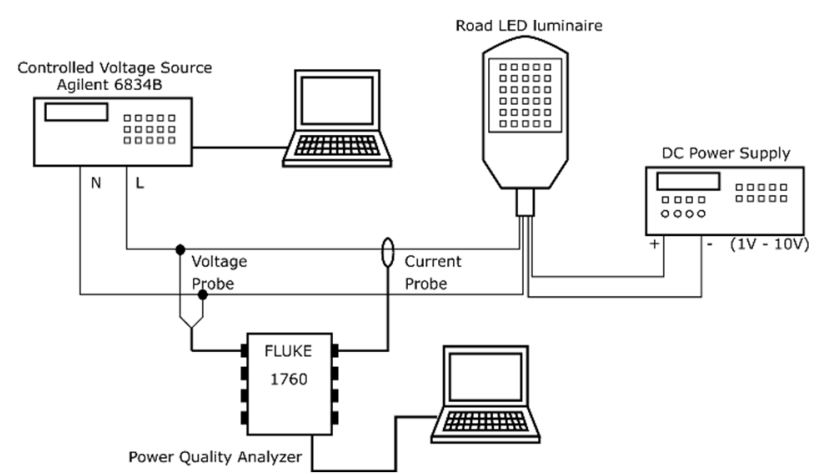

(b)

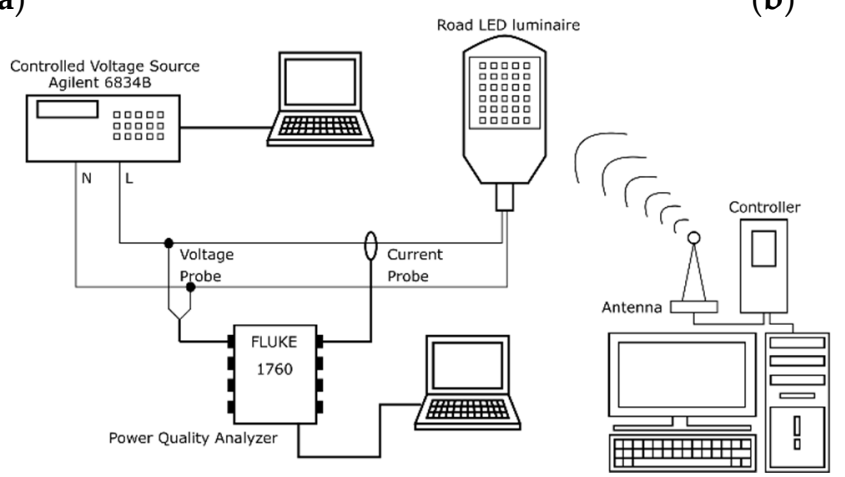

(c)

Figure 1. Measurement diagrams used to: (a) measure the RMS (Root Mean Square) value and deformation of the supply voltage, (b) measure the control characteristics of the light-emitting diode (LED4) luminaire, (c) measure the control characteristics of the LED3 luminaire.

Figure 2 presents the spectra of higher harmonics of the supply voltages used during measurements related to the fundamental harmonics $(50 \mathrm{~Hz})$ and phase angles of harmonics. In each case the RMS value of the fundamental harmonic of the supply voltage was $230 \mathrm{~V}$. Higher harmonics of the supply voltage for $T H D_{V}=1.79 \%$ were obtained from the measurements made in the real road lighting installation. For other $T H D_{V}$ values, individual harmonics were increased proportionally to obtain the assumed $T H D_{V}$ value.

For the presentation of the influence of dimming on the electrical parameters of the road luminaire, two luminaires with different construction, rated power and control have been selected. The first LED3 luminaire was dimmed by applying a control voltage to the analogue input $(1 \mathrm{~V}-10 \mathrm{~V})$. The dimming was implemented using a stabilized power supply that is a source of control voltage. The measurement system is shown in Figure 1b. The second LED4 luminaire is dimmed by a wireless communication system. The control system consisted of a server with a dedicated application, a control system, and an antenna. The measuring system and the control system are shown in Figure 1c. Both luminaires were supplied with a sinusoidal voltage in the effective value of the supply voltage equal to $230 \mathrm{~V}$. 


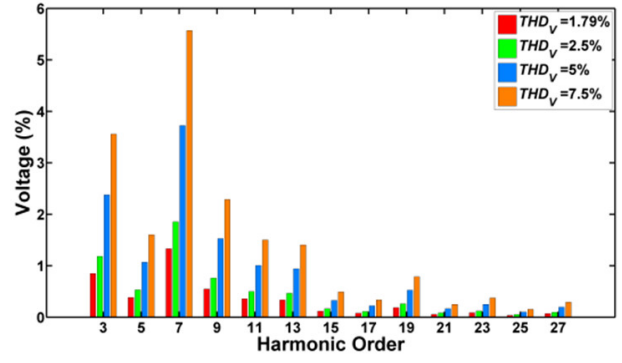

(a)

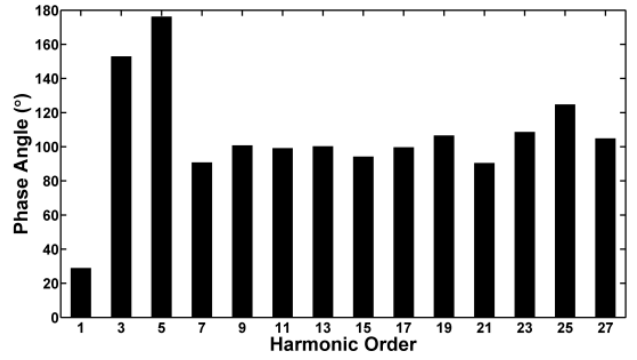

(b)

Figure 2. Harmonics spectra of the supply voltage (a) used during measurements and (b) their phase angle.

\section{The Results of Laboratory Tests}

\subsection{Studies of the Influence of RMS Value of Supply Voltage}

Lighting luminaire made in LED technology should be insensitive to changes in the RMS value of the supply voltage due to the structure of the electronic power supply. Assumed insensitivity should concern basic electrical parameters such as active power, reactive power, current to take from the mains, and power factor. In order to verify the relationship in this field at a later stage of the research laboratory four LED luminaires were verified. The lighting luminaires of different rated power and various manufacturers were selected for research. For the purposes of the study, they were marked as LUM1, LUM2, LUM3 and LUM4. Tables 1-4 present the measured and calculated electrical parameters according to the dependencies presented in Section 2 of the LED luminaires tested in the assumed range of voltage variations from $207 \mathrm{~V}$ to $253 \mathrm{~V}$. The luminaires are supplied with non-deformed voltage. In the tables, $3 \%$ deviations were introduced $\left(\Delta X_{\text {Lim }}, \Delta X_{\text {LimB }}, \Delta X_{\text {LimT }}\right)$ which are defined as follows:

$$
\begin{aligned}
\Delta X_{\text {Lim }} & =\left(\left(X_{253 V}-X_{207 V}\right) / X_{207 V}\right) \cdot 100 \% \\
\Delta X_{L i m B} & =\left(\left(X_{207 V}-X_{230 V}\right) / X_{230 V}\right) \cdot 100 \% \\
\Delta X_{L i m T} & =\left(\left(X_{253 V}-X_{230 V}\right) / X_{230 V}\right) \cdot 100 \%
\end{aligned}
$$

\begin{tabular}{|c|c|c|c|c|c|c|c|c|c|c|c|c|}
\hline $\begin{array}{c}V \\
(\mathrm{~V})\end{array}$ & $\begin{array}{c}I \\
(\mathrm{~mA})\end{array}$ & $\begin{array}{c}I_{1} \\
(\mathrm{~mA})\end{array}$ & $\begin{array}{c}I_{H} \\
(\mathrm{~mA})\end{array}$ & $\begin{array}{c}T H D_{I} \\
(\%)\end{array}$ & $\begin{array}{c}P \\
(W)\end{array}$ & $\begin{array}{c}S \\
\text { (VA) }\end{array}$ & $\begin{array}{c}S_{1} \\
\text { (VA) }\end{array}$ & $\begin{array}{c}D_{I} \\
\text { (var) }\end{array}$ & $\begin{array}{c}Q \\
\text { (var) }\end{array}$ & $\cos \varphi$ & $P F$ & $\tan \varphi$ \\
\hline 207 & 514.90 & 512.50 & 49.66 & 9.64 & 103.67 & 106.53 & 106.03 & 10.27 & 22.269 & 0.978 & 0.973 & 0.215 \\
\hline 215 & 496.60 & 494.13 & 49.47 & 9.96 & 103.53 & 106.72 & 106.19 & 10.63 & 23.605 & 0.975 & 0.970 & 0.228 \\
\hline 220 & 486.21 & 483.70 & 49.34 & 10.14 & 103.52 & 106.92 & 106.37 & 10.85 & 24.472 & 0.973 & 0.968 & 0.236 \\
\hline 225 & 476.24 & 473.70 & 49.12 & 10.29 & 103.5 & 107.13 & 106.56 & 11.05 & 25.349 & 0.971 & 0.966 & 0.245 \\
\hline 240 & 449.85 & 447.20 & 48.76 & 10.82 & 103.56 & 107.93 & 107.29 & 11.70 & 28.033 & 0.965 & 0.960 & 0.271 \\
\hline 245 & 441.55 & 438.84 & 48.85 & 11.06 & 103.51 & 108.15 & 107.49 & 11.96 & 28.96 & 0.963 & 0.957 & 0.280 \\
\hline 250 & 433.77 & 431.00 & 48.94 & 11.29 & 103.49 & 108.42 & 107.73 & 12.23 & 29.916 & 0.961 & 0.955 & 0.289 \\
\hline 253 & 429.30 & 426.48 & 49.13 & 11.44 & 103.49 & 108.59 & 107.88 & 12.43 & 30.43 & 0.959 & 0.953 & 0.294 \\
\hline$\Delta X_{L i m}(\%)$ & -16.62 & -16.78 & -1.07 & 18.69 & -0.17 & 1.93 & 1.74 & 20.96 & 36.65 & -1.87 & -2.06 & 36.89 \\
\hline
\end{tabular}

Table 1. Summary of the measured values of the electrical parameters of the lighting luminaires marked as LUM1. 
Table 2. Summary of the measured values of the electrical parameters of the lighting luminaires marked as LUM2.

\begin{tabular}{|c|c|c|c|c|c|c|c|c|c|c|c|c|}
\hline $\begin{array}{c}V \\
\text { (V) }\end{array}$ & $\begin{array}{c}I \\
(\mathrm{~mA})\end{array}$ & $\begin{array}{c}I_{1} \\
(\mathrm{~mA})\end{array}$ & $\begin{array}{c}I_{H} \\
(\mathrm{~mA})\end{array}$ & $\begin{array}{c}\text { THD } \\
(\%)\end{array}$ & $\begin{array}{c}P \\
(W)\end{array}$ & $\begin{array}{c}S \\
\text { (VA) }\end{array}$ & $\begin{array}{c}S_{1} \\
\text { (VA) }\end{array}$ & $\begin{array}{c}D_{I} \\
\text { (var) }\end{array}$ & $\underset{\text { (var) }}{Q}$ & $\cos \varphi$ & $P F$ & $\tan \varphi$ \\
\hline 207 & 169.39 & 168.05 & 21.26 & 12.52 & 32.60 & 35.07 & 34.79 & 4.40 & 12.15 & 0.937 & 0.930 & 0.373 \\
\hline 210 & 167.36 & 166.00 & 21.29 & 12.69 & 32.55 & 35.15 & 34.86 & 4.47 & 12.48 & 0.934 & 0.926 & 0.384 \\
\hline 215 & 164.29 & 162.90 & 21.33 & 12.96 & 32.54 & 35.33 & 35.03 & 4.59 & 12.96 & 0.929 & 0.921 & 0.398 \\
\hline 220 & 161.58 & 160.15 & 21.45 & 13.26 & 32.55 & 35.56 & 35.24 & 4.72 & 13.50 & 0.924 & 0.916 & 0.415 \\
\hline 225 & 158.74 & 157.21 & 21.99 & 13.84 & 32.50 & 35.73 & 35.38 & 4.95 & 14.00 & 0.918 & 0.910 & 0.431 \\
\hline 230 & 156.27 & 154.74 & 21.81 & 13.94 & 32.48 & 35.95 & 35.60 & 5.02 & 14.57 & 0.912 & 0.903 & 0.449 \\
\hline 235 & 153.99 & 152.47 & 21.58 & 13.98 & 32.49 & 36.20 & 35.84 & 5.07 & 15.14 & 0.906 & 0.897 & 0.466 \\
\hline 240 & 152.05 & 150.55 & 21.30 & 14.01 & 32.53 & 36.50 & 36.14 & 5.11 & 15.75 & 0.900 & 0.891 & 0.484 \\
\hline 245 & 150.07 & 148.58 & 21.09 & 14.05 & 32.53 & 36.77 & 36.41 & 5.17 & 16.34 & 0.894 & 0.885 & 0.502 \\
\hline 250 & 148.13 & 146.66 & 20.82 & 14.07 & 32.54 & 37.04 & 36.67 & 5.20 & 16.90 & 0.887 & 0.879 & 0.519 \\
\hline 253 & 147.03 & 145.56 & 20.74 & 14.06 & 32.52 & 37.20 & 36.83 & 5.25 & 17.29 & 0.883 & 0.874 & 0.532 \\
\hline$\Delta X_{\text {Lim }}(\%)$ & -13.20 & -13.38 & -2.47 & 12.28 & -0.24 & 6.08 & 5.86 & 19.20 & 42.23 & -5.76 & -5.96 & 42.57 \\
\hline$\Delta X_{\text {LimB }}(\%)$ & 8.40 & 8.60 & -2.52 & -10.17 & 0.36 & -2.46 & -2.27 & -12.28 & -16.58 & 2.69 & 2.89 & -16.88 \\
\hline$\Delta X_{\text {Lim } T}(\%)$ & -5.91 & -5.93 & -4.93 & 0.86 & 0.12 & 3.48 & 3.45 & 4.56 & 18.66 & -3.22 & -3.24 & 18.51 \\
\hline
\end{tabular}

Table 3. Summary of the measured values of the electrical parameters of the lighting luminaires marked as LUM3.

\begin{tabular}{|c|c|c|c|c|c|c|c|c|c|c|c|c|}
\hline $\begin{array}{c}V \\
(\mathrm{~V})\end{array}$ & $\begin{array}{c}I \\
(\mathrm{~mA})\end{array}$ & $\begin{array}{c}I_{1} \\
(\mathrm{~mA})\end{array}$ & $\begin{array}{c}I_{H} \\
(\mathrm{~mA})\end{array}$ & $\begin{array}{c}T H D_{I} \\
(\%)\end{array}$ & $\begin{array}{c}P \\
(W)\end{array}$ & $\begin{array}{c}S \\
\text { (VA) }\end{array}$ & $\begin{array}{c}S_{1} \\
\text { (VA) }\end{array}$ & $\begin{array}{c}D_{I} \\
\text { (var) }\end{array}$ & $\underset{\text { (var) }}{Q}$ & $\cos \varphi$ & $P F$ & $\tan \varphi$ \\
\hline 207 & 435.99 & 272.66 & 340.21 & 124.69 & 50.38 & 90.24 & 56.44 & 70.42 & 25.05 & 0.895 & 0.558 & 0.497 \\
\hline 210 & 437.58 & 274.77 & 340.55 & 123.86 & 51.50 & 91.87 & 57.69 & 71.50 & 25.61 & 0.895 & 0.561 & 0.497 \\
\hline 215 & 443.60 & 278.00 & 345.68 & 124.25 & 53.41 & 95.37 & 59.76 & 74.32 & 26.43 & 0.896 & 0.560 & 0.495 \\
\hline 220 & 466.75 & 287.74 & 367.51 & 127.54 & 56.54 & 102.69 & 63.31 & 80.86 & 28.03 & 0.896 & 0.551 & 0.496 \\
\hline 225 & 472.66 & 290.61 & 372.76 & 128.10 & 58.44 & 106.35 & 65.39 & 83.87 & 28.87 & 0.897 & 0.550 & 0.494 \\
\hline 230 & 478.56 & 293.55 & 377.95 & 128.58 & 60.42 & 110.08 & 67.52 & 86.94 & 29.68 & 0.898 & 0.549 & 0.491 \\
\hline 235 & 484.26 & 296.39 & 382.96 & 129.04 & 62.39 & 113.82 & 69.66 & 90.01 & 30.51 & 0.898 & 0.548 & 0.489 \\
\hline 240 & 490.15 & 299.48 & 388.02 & 129.40 & 64.41 & 117.62 & 71.86 & 93.11 & 31.38 & 0.899 & 0.548 & 0.487 \\
\hline 245 & 495.87 & 302.36 & 393.02 & 129.82 & 66.46 & 121.47 & 74.07 & 96.28 & 32.19 & 0.900 & 0.547 & 0.484 \\
\hline 250 & 501.82 & 305.57 & 398.06 & 130.12 & 68.57 & 125.44 & 76.39 & 99.51 & 33.13 & 0.900 & 0.547 & 0.483 \\
\hline 253 & 505.55 & 308.24 & 400.71 & 129.87 & 70.03 & 127.90 & 77.98 & 101.38 & 33.76 & 0.901 & 0.548 & 0.482 \\
\hline$\Delta X_{\text {Lim }}(\%)$ & 15.95 & 13.05 & 17.78 & 4.15 & 39.01 & 41.73 & 38.18 & 43.96 & 34.78 & 0.60 & -1.91 & -3.04 \\
\hline$\Delta X_{\text {LimB }}(\%)$ & -8.90 & -7.12 & -9.99 & -3.03 & -16.61 & -18.02 & -16.42 & -19.00 & -15.59 & -0.24 & 1.71 & 1.23 \\
\hline$\Delta X_{\text {LimT }}(\%)$ & 5.64 & 5.00 & 6.02 & 1.00 & 15.92 & 16.19 & 15.49 & 16.61 & 13.77 & 0.36 & -0.23 & -1.85 \\
\hline
\end{tabular}

Table 4. Summary of the measured values of the electrical parameters of the lighting luminaires marked as LUM4.

\begin{tabular}{|c|c|c|c|c|c|c|c|c|c|c|c|c|}
\hline $\begin{array}{c}V \\
(\mathrm{~V})\end{array}$ & $\begin{array}{c}I \\
(\mathrm{~mA})\end{array}$ & $\begin{array}{c}I_{1} \\
(\mathrm{~mA})\end{array}$ & $\begin{array}{c}I_{H} \\
(\mathbf{m A})\end{array}$ & $\begin{array}{c}T H D_{I} \\
(\%)\end{array}$ & $\begin{array}{c}P \\
(W)\end{array}$ & $\begin{array}{c}S \\
\text { (VA) }\end{array}$ & $\begin{array}{c}S_{1} \\
\text { (VA) }\end{array}$ & $\begin{array}{c}D_{I} \\
\text { (var) }\end{array}$ & $\underset{\text { (var) }}{Q}$ & $\cos \varphi$ & $P F$ & $\tan \varphi$ \\
\hline 207 & 274.85 & 269.33 & 54.81 & 20.30 & 54.31 & 56.89 & 55.74 & 11.34 & 12.54 & 0.974 & 0.955 & 0.231 \\
\hline 210 & 272.21 & 266.66 & 54.69 & 20.47 & 54.48 & 57.16 & 56.00 & 11.48 & 12.91 & 0.973 & 0.953 & 0.237 \\
\hline 215 & 266.74 & 261.16 & 54.27 & 20.73 & 54.50 & 57.34 & 56.14 & 11.67 & 13.46 & 0.971 & 0.950 & 0.247 \\
\hline 220 & 261.87 & 256.24 & 54.01 & 21.02 & 54.60 & 57.61 & 56.37 & 11.88 & 14.01 & 0.969 & 0.948 & 0.257 \\
\hline 225 & 256.59 & 250.93 & 53.60 & 21.30 & 54.54 & 57.73 & 56.46 & 12.06 & 14.58 & 0.966 & 0.945 & 0.267 \\
\hline 230 & 251.65 & 245.99 & 53.07 & 21.51 & 54.49 & 57.88 & 56.58 & 12.21 & 15.19 & 0.963 & 0.941 & 0.279 \\
\hline 235 & 246.62 & 240.94 & 52.62 & 21.77 & 54.38 & 57.97 & 56.63 & 12.37 & 15.77 & 0.960 & 0.938 & 0.290 \\
\hline 240 & 241.82 & 236.13 & 52.15 & 22.03 & 54.24 & 58.03 & 56.67 & 12.51 & 16.37 & 0.957 & 0.935 & 0.302 \\
\hline 245 & 237.16 & 231.47 & 51.64 & 22.24 & 54.10 & 58.10 & 56.71 & 12.65 & 16.98 & 0.954 & 0.931 & 0.314 \\
\hline 250 & 233.78 & 228.06 & 51.40 & 22.46 & 54.21 & 58.45 & 57.02 & 12.85 & 17.66 & 0.951 & 0.927 & 0.326 \\
\hline 253 & 231.82 & 226.09 & 51.22 & 22.59 & 54.27 & 58.65 & 57.20 & 12.96 & 18.05 & 0.949 & 0.925 & 0.333 \\
\hline$\Delta X_{\text {Lim }}(\%)$ & -15.66 & -16.05 & -6.54 & 11.27 & -0.06 & 3.11 & 2.62 & 14.25 & 43.93 & -2.61 & -3.07 & 44.02 \\
\hline$\Delta X_{\text {LimB }}(\%)$ & 9.22 & 9.49 & 3.27 & -5.60 & -0.34 & -1.72 & -1.47 & -7.07 & -17.45 & 1.15 & 1.40 & -17.17 \\
\hline$\Delta X_{\operatorname{Lim} T}(\%)$ & -7.88 & -8.09 & -3.48 & 5.04 & -0.41 & 1.34 & 1.11 & 6.17 & 18.81 & -1.49 & -1.72 & 19.30 \\
\hline
\end{tabular}

For the measurement data contained in Tables from 1 to 4 , the reference value is the supply voltage value equal to $230 \mathrm{~V}$. The introduced additional deviations described in Formulas (21), (22) and (23) allow to evaluate the effect of the RMS value of the supply voltage on the value of the distinctive electrical parameter. The coefficient defined as (22) shows the changes caused by the voltage drop below the reference value, and defined as (23) the changes caused by its increase, respectively.

Analysing the obtained results sensitive to the change of the supply voltage are the RMS value of the supply current $I$, reactive power $Q$, current distortion power $D_{I}$. The tables do not include the 
power values $P_{H}, D_{V}, S_{N}$ and $S_{H}$ because for sinusoidal voltage $\left(T H D_{V}=0 \%\right)$ they are equal to 0 . For all tested luminaires, an increase in the RMS value of the supply voltage results in a reduction of the RMS value of the supply current and these changes are calculated at a level of a dozen or so percent from the relation (21). The values of deviations calculated from dependencies (22) and (23) prove that the luminaires are more sensitive in respect to the voltage deviation below the reference value of $230 \mathrm{~V}$. The reactive power $Q$ is more sensitive to the changes in the supply voltage and it varies from $35 \%$ to $44 \%$ for the luminaires tested. Similarly, the deformation power $D$ is maintained, which varies from $14 \%$ to even $44 \%$. A correctly designed power supply for the luminaire within the permissible limits of the supply voltage should take from the grid a constant active power $P$, which was confirmed for the LUM1, LUM2 and LUM4 luminaires. Here the deviations obtained are below $1 \%$. The LUM3 luminaire behaves in a different way, because the change of the supply voltage within the considered limits causes the change of the active power consumed from the network by as much as $39 \%$. Apparent power $S$ for each tested luminaire increases with the supply voltage in the range from $2 \%$ to $41 \%$ depending on the type of luminaire. Changes in the degree of deformation of the supply current caused by changes in the supply voltage are described by the variability of the $T H D_{I}$ coefficient. For this parameter, these changes range from $4 \%$ to $19 \%$. The LUM3 luminaire is the least sensitive in this respect.

Among the analysed electrical parameters we can recognize those that are not particularly sensitive to changes in the supply voltage. The $\cos \varphi$ power factor is such a parameter. A change in the supply voltage in a given range causes a change in its value depending on the type of the luminaire from $0.6 \%$ to $5.7 \%$. It can be observed that the increase in the supply voltage causes a slight increase in its value. In contrast to $\cos \varphi$, the power factor defined as $P F$ decreases with the increase of the supply voltage, and its registered changes were at the level of $2 \%$ to $6 \%$. Therefore, it can be concluded that the parameter is also not very sensitive to the changes in the supply voltage.

Figures 3-6 present the recorded instantaneous waveforms of currents taken from the mains and supply voltages and current harmonic spectra. The highest level of power supply distortion occurs for the LUM3 luminaire. The power supply in this luminaire is not equipped with a PFC system, which means that the THD current of this power supply for the $230 \mathrm{~V}$ voltage is $128.58 \%$. The third harmonic current of this luminaire is over $85 \%$ in relation to the fundamental harmonic. The power supplies in the other luminaires are equipped with EMI filters and PFC systems. As a result, the generated higher harmonics of the current to the supply network are limited. The harmonics of orders 3,5 and 7 are dominated for all luminaires.

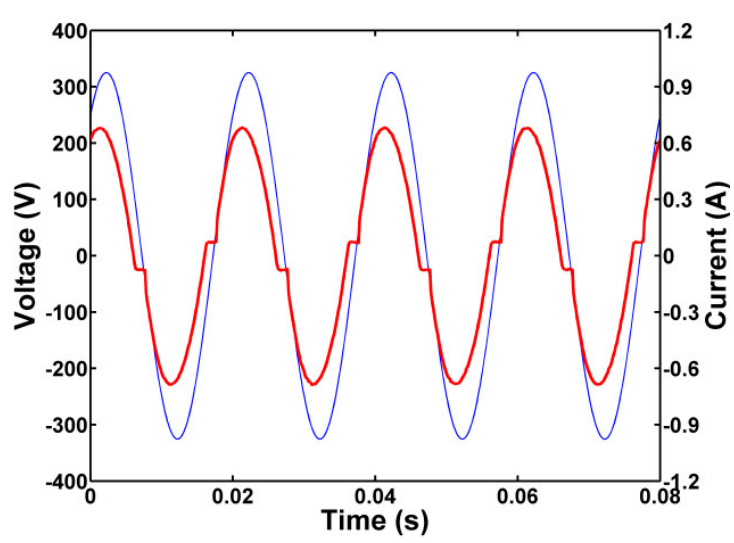

(a)

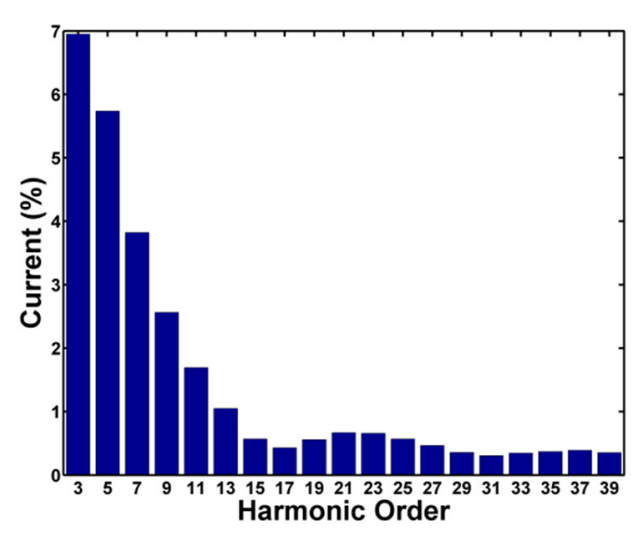

(b)

Figure 3. Waveforms of instantaneous values of current and voltage (a) for luminaire marked as LUM1 and (b) current harmonic spectrum. 


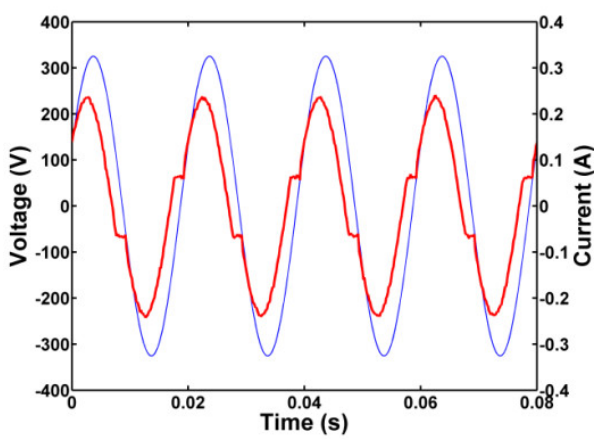

(a)

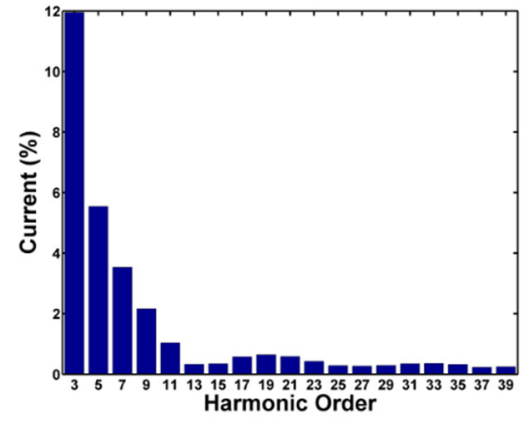

(b)

Figure 4. Waveforms of instantaneous values of current and voltage (a) for luminaire marked as LUM2 and (b) current harmonic spectrum.

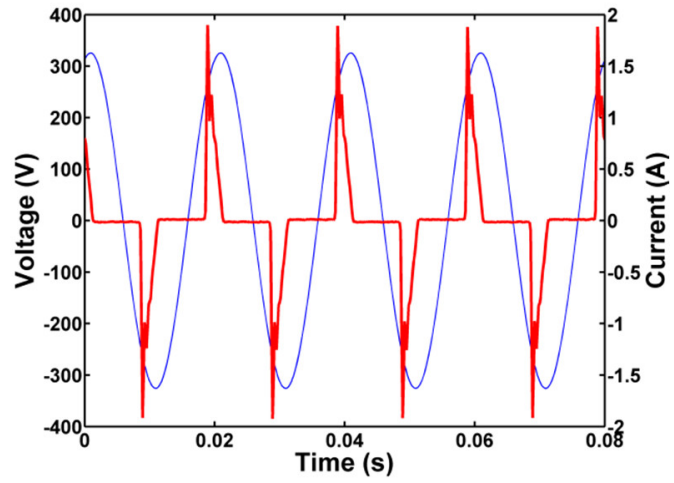

(a)

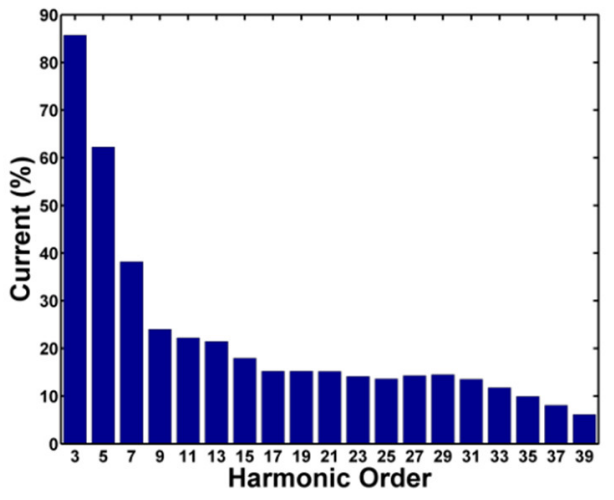

(b)

Figure 5. Waveforms of instantaneous values of current and voltage (a) for luminaire marked as LUM3 and (b) current harmonic spectrum.

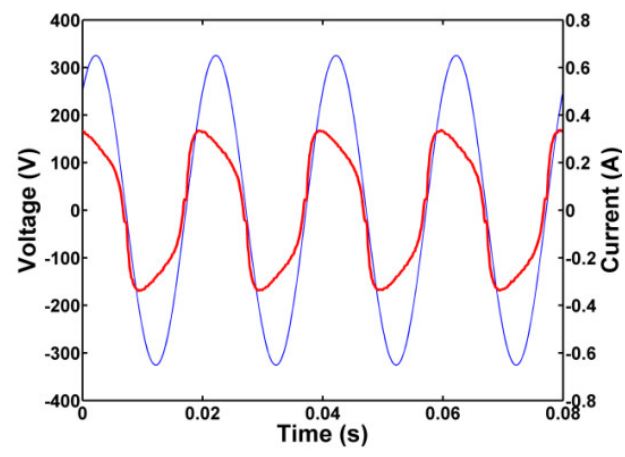

(a)

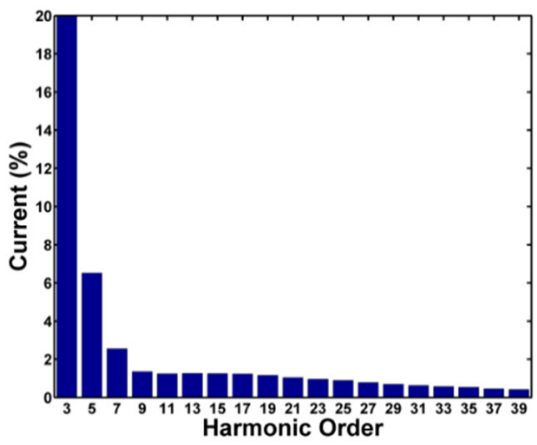

(b)

Figure 6. Waveforms of instantaneous values of current and voltage (a) for luminaire marked as LUM4 and (b) current harmonic spectrum.

\subsection{Studies of the Effect of the Level of Supply Voltage Distortion}

In the first stage of the laboratory tests, two luminaires made in LED technology designated as LED1 and LED2 were selected. The value of $T H D_{V}$ coefficient of the supply voltage is a measure of the power quality here. For the laboratory tests, the choice of lighting luminaires was made in such a way that the most typical of their construction solutions could be assessed in this respect. Tables 5 and 6 present measured and calculated values of electrical parameters for LED1 and LED2, respectively, at different levels of voltage distortion. 
Table 5. Summary of measured and calculated values of electrical parameters of the LED1 luminaire at a change in the level of deformation of the supply voltage.

\begin{tabular}{|c|c|c|c|c|c|c|c|c|c|c|c|c|c|c|c|c|c|c|c|c|}
\hline $\begin{array}{l}T H D_{V} \\
\text { (\%) }\end{array}$ & $\begin{array}{c}V \\
\text { (V) }\end{array}$ & $\begin{array}{l}V_{1} \\
(\mathrm{~V})\end{array}$ & $\begin{array}{l}V_{H} \\
\text { (V) }\end{array}$ & $\begin{array}{c}I \\
(\mathrm{~mA})\end{array}$ & $\begin{array}{c}I_{1} \\
(\mathrm{~mA})\end{array}$ & $\begin{array}{c}I_{H} \\
(\mathrm{~mA})\end{array}$ & $\begin{array}{c}T H D_{I} \\
(\%)\end{array}$ & $\begin{array}{c}P \\
(W)\end{array}$ & $\begin{array}{c}P_{1} \\
\text { (W) }\end{array}$ & $\begin{array}{c}P_{H} \\
\text { (W) }\end{array}$ & $\begin{array}{c}S \\
\text { (VA) }\end{array}$ & $\begin{array}{c}S_{1} \\
\text { (VA) }\end{array}$ & $\begin{array}{c}S_{N} \\
\text { (VA) }\end{array}$ & $\begin{array}{c}S_{H} \\
\text { (VA) }\end{array}$ & $\begin{array}{c}D_{I} \\
\text { (var) }\end{array}$ & $\begin{array}{c}D_{V} \\
\text { (var) }\end{array}$ & $\begin{array}{c}Q \\
\text { (var) }\end{array}$ & $\cos \varphi$ & $P F$ & $\tan \varphi$ \\
\hline 0 & 230.10 & 230.10 & 0.00 & 648.29 & 646.00 & 54.42 & 8.10 & 142.42 & 142.39 & 0.03 & 14917 & 148.64 & 12.52 & 0.00 & 12.52 & 0.00 & 42.67 & & 0.95 & .30 \\
\hline 1.79 & 0.11 & 206 & & & & & & & & & & & & & & & & 6 & 95 & 0.30 \\
\hline 2.50 & & & & & & & & & & & & & & & & & & & & 0.30 \\
\hline 5.00 & م10 & 9.81 & 11.5 & & & & & & & & & & & & & & & & & 0.29 \\
\hline 7.50 & 230.08 & 229.44 & 17.15 & 652.20 & 643.90 & 103.74 & 15.99 & 142.31 & 141.69 & 0.62 & 150.06 & 147.74 & 26.30 & 1.78 & 23.80 & 11.04 & 41.07 & 0.96 & 0.95 & 0.29 \\
\hline
\end{tabular}

Table 6. Summary of measured and calculated values of electrical parameters of the LED2 luminaire at a change in the level of deformation of the supply voltage.

\begin{tabular}{|c|c|c|c|c|c|c|c|c|c|c|c|c|c|c|c|c|c|c|c|c|}
\hline $\begin{array}{l}T_{H} D_{V} \\
(\%)\end{array}$ & $\begin{array}{c}V \\
(\mathrm{~V})\end{array}$ & $\begin{array}{c}V_{1} \\
(\mathrm{~V})\end{array}$ & $\begin{array}{l}V_{H} \\
(\mathrm{~V})\end{array}$ & $\begin{array}{c}I \\
(\mathrm{~mA})\end{array}$ & $\begin{array}{c}I_{1} \\
(\mathrm{~mA})\end{array}$ & $\begin{array}{c}I_{H} \\
(\mathrm{~mA})\end{array}$ & $\begin{array}{c}T H D_{I} \\
(\%)\end{array}$ & $\begin{array}{c}P \\
(W)\end{array}$ & $\begin{array}{c}P_{1} \\
\text { (W) }\end{array}$ & $\begin{array}{c}P_{H} \\
\text { (W) }\end{array}$ & $\begin{array}{c}S \\
\text { (VA) }\end{array}$ & $\begin{array}{c}S_{1} \\
\text { (VA) }\end{array}$ & $\begin{array}{c}S_{N} \\
\text { (VA) }\end{array}$ & $\begin{array}{c}S_{H} \\
\text { (VA) }\end{array}$ & $\begin{array}{c}D_{\mathrm{I}} \\
\text { (var) }\end{array}$ & $\begin{array}{c}D_{V} \\
\text { (var) }\end{array}$ & $\underset{\text { (var) }}{Q}$ & $\cos \varphi$ & $P F$ & $\tan \varphi$ \\
\hline 0 & 230.21 & 230.21 & 0.00 & 348.87 & 344.10 & 57.51 & 16.42 & 74.36 & 74.34 & 0.02 & 80.31 & 79.22 & 13.24 & 0.00 & 13.24 & 0.00 & 27.38 & & 0.93 & 0.37 \\
\hline 1.79 & & & & & & & & & & & & & & & & & & & & 0.37 \\
\hline 2.50 & 0.21 & 0.13 & 6.07 & 8.41 & & 58.90 & & 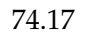 & 08 & 0. & & 9.03 & 2 & 0.3 & & 2.08 & 52 & 0.94 & 0.92 & 0.37 \\
\hline 5.00 & 230.19 & 229.89 & 11.71 & 349.92 & 343.50 & 66.70 & 19.11 & 74.20 & 73.99 & 0.22 & 80.55 & 78.97 & 15.87 & 0.78 & 15.33 & 4.02 & 27.59 & 0.94 & 0.92 & 0.37 \\
\hline 7.50 & 230.19 & 229.57 & 16.86 & 352.21 & 343.60 & 77.40 & 22.33 & 74.22 & 73.84 & 0.38 & 81.08 & 78.88 & 18.73 & 1.30 & 17.77 & 5.79 & 27.48 & 0.94 & 0.92 & 0.37 \\
\hline
\end{tabular}


The $V_{H}$ voltage value for the LED1 luminaire ranges from $0 \%$ to $17.15 \%$ and the $I_{H}$ current values from $54.42 \mathrm{~mA}$ to $103.74 \mathrm{~mA}$. This is almost a two-fold increase in this current. This is the reason for the increase in the $T H D_{I}$ value from $8.10 \%$ to $15.99 \%$. This is a significant increase of $97.41 \%$. The value of the first harmonic current I1 practically does not change. The increase in the RMS value of the luminaire current is due to the increase in the value of higher harmonic currents. The active power $P$ of the luminaire does not depend on the level of deformation of the supply voltage. Observed for the dependence of the active power $P_{H}$ and the power of $S_{N}, S_{H}, D_{I}$ and $D_{V}$. The value of $D_{I}$ power increased by $90.10 \%$ from 12.52 var to 23.80 var. The reactive power of the $Q$ is capacitive and practically does not depend on the deformation of the supply voltage. The influence of the voltage level of the supply voltage on the power factors $\cos \varphi, P F$ and $\tan \varphi$ is also not observed. The largest increase in value was observed for the power of $P_{H}$. When supplied with a sinusoidal voltage $P_{H}=0.03 \mathrm{~W}$. After powering the luminaire with distorted voltage $T H D_{V}=7.50 \%$ power $P_{H}=0.62 \mathrm{~W}$. There was an increase of this power by $1996.66 \%$.

Analysing the results of the measurements and calculations for the LED2 luminaire, similar phenomena are observed as for the LED1 luminaire. The voltage $V_{H}$ increases with the level of voltage deformation to $16.86 \mathrm{~V}$ with $T H D_{V}=7.50 \%$. The $I_{H}$ current also increases along with the value of $57.51 \mathrm{~mA}$ (for $T H D_{V}=0 \%$ ) to the value of $77.40 \%$ (for $T H D_{V}=7.50 \%$ ), i.e., by $34.58 \%$. The measured $T H D_{I}$ value when supplying the luminaire with non-deformed voltage is $16.42 \%$ and increases up to $22.33 \%$ if the luminaire is supplied with a voltage distorted by $T H D_{V}=7.50 \%$. The $T H D_{I}$ value increases by $36 \%$. In comparison to LED1, this is a much smaller increase in this coefficient. Therefore, it can be concluded that the influence of the voltage level of the supply voltage on the level of generated harmonic currents by LED2 is much smaller. The value of the $P_{H}$ power increases with the level of deformation of the supply voltage from the value of $0.02 \mathrm{~W}$ to the value of $0.38 \mathrm{~W}$. This is a very large increase of $1800 \%$, although the values of this power compared to the power $P$ of the luminaire are very small. Along with the increase of voltage supply strain, the power values of $D_{I}$ and $S_{N}$ increase by $34.21 \%$ and $41.47 \%$, respectively. Also in the case of this luminaire there was no large dependence of reactive power $Q$ and power factors on the level of voltage deformation.

Figures 7 and 8 show the waveforms of currents and voltages for the analysed luminaires. For comparison purposes, the measured waveforms for the two extreme levels of the supply current distortion, namely the sinusoidal voltage $T H D_{V}=0 \%$ and the deformation voltage $T H D_{V}=7.5 \%$, were measured.

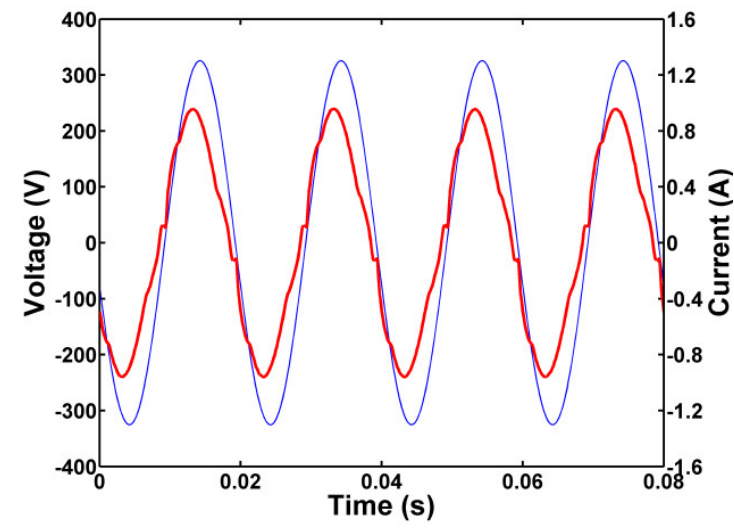

(a)

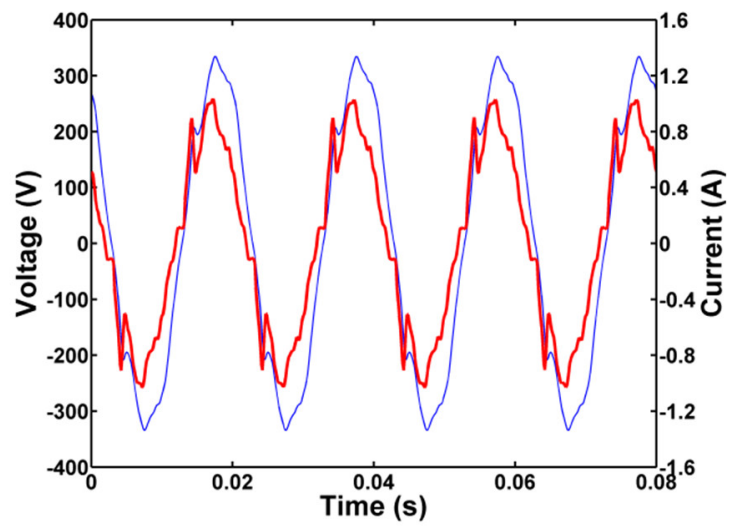

(b)

Figure 7. Waveforms of voltage and current for luminaire marked as LED1 for: (a) $T H D_{V}=0 \%$ and (b) $T H D_{V}=7.5 \%$. 


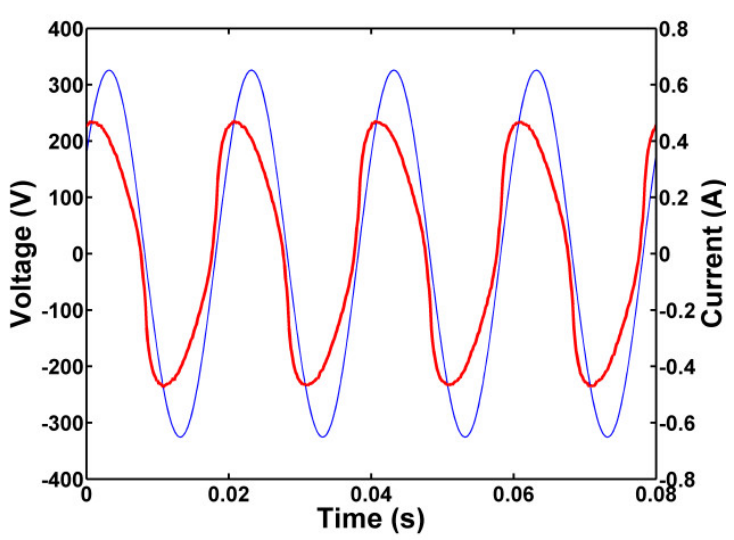

(a)

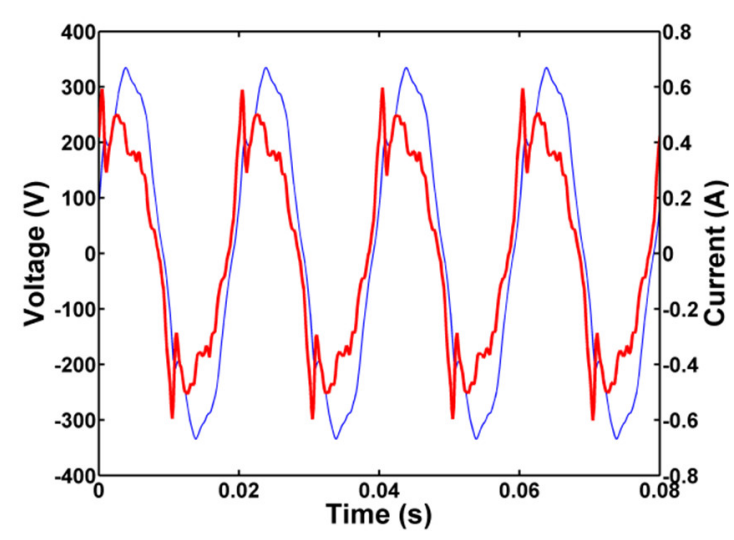

(b)

Figure 8. Waveforms of voltage and current for luminaire marked as LED2 for: (a) $T H D_{V}=0 \%$ and (b) $T H D_{V}=7.5 \%$.

The higher harmonics of the supply current were also determined. Measured percentage RMS values of selected harmonics in relation to the basic harmonic for the tested luminaires are presented in Tables 7 and 8. For all tested luminaires, the increase in the level of deformation of the supply voltage results in a decrease of the harmonic percentage of the order of 3 in relation to the basic harmonic. In the case of harmonics of the order of 5 or higher, the increase in the deformation level of the supply voltage causes the harmonic share of a given order to increase or to maintain at the same level in relation to the basic harmonic. Analysing the obtained spectrum of the supply current, a noticeable increase in the share of individual harmonics to order of 11 can be seen. Harmonics of higher orders than 11 harmonics are clearly below 5\% of the fundamental harmonics. For the highest level of voltage supply deformation $\left(T H D_{V}=7.5 \%\right)$ the highest share in the total spectrum of the supply current has a harmonic of $7(350 \mathrm{~Hz})$ and is respectively $11.01 \%$ and $13.46 \%$ for LED1 and LED2.

Table 7. List of measured selected RMS values of harmonics $I_{h}$ in relation to the basic harmonics for LED1.

\begin{tabular}{cccccccccccccc}
\hline $\begin{array}{c}\mathbf{T H D}_{V} \\
\mathbf{( \% )}\end{array}$ & $\begin{array}{c}\boldsymbol{I}_{\mathbf{3}} \\
\mathbf{( \% )}\end{array}$ & $\begin{array}{c}\boldsymbol{I}_{\mathbf{5}} \\
\mathbf{( \% )}\end{array}$ & $\begin{array}{c}\boldsymbol{I}_{\mathbf{7}} \\
\mathbf{( \% )}\end{array}$ & $\begin{array}{c}\boldsymbol{I}_{\mathbf{9}} \\
\mathbf{( \% )}\end{array}$ & $\begin{array}{c}\boldsymbol{I}_{\mathbf{1 1}} \\
\mathbf{( \% )}\end{array}$ & $\begin{array}{c}\boldsymbol{I}_{\mathbf{1 3}} \\
\mathbf{( \% )}\end{array}$ & $\begin{array}{c}\boldsymbol{I}_{\mathbf{1 5}} \\
\mathbf{( \% )}\end{array}$ & $\begin{array}{c}\boldsymbol{I}_{\mathbf{1}} \\
\mathbf{( \% )}\end{array}$ & $\begin{array}{c}\boldsymbol{I}_{\mathbf{1 9}} \\
\mathbf{( \% )}\end{array}$ & $\begin{array}{c}\boldsymbol{I}_{\mathbf{2 1}} \\
\mathbf{( \% )}\end{array}$ & $\begin{array}{c}\boldsymbol{I}_{\mathbf{2 3}} \\
\mathbf{( \% )}\end{array}$ & $\begin{array}{c}\boldsymbol{I}_{\mathbf{2 5}} \\
\mathbf{( \% )}\end{array}$ & $\begin{array}{c}\boldsymbol{I}_{\mathbf{2 7}} \\
\mathbf{( \% )}\end{array}$ \\
\hline 0 & 5.94 & 3.34 & 1.31 & 2.37 & 2.20 & 1.21 & 0.95 & 1.25 & 1.22 & 0.74 & 0.44 & 0.43 & 0.43 \\
1.79 & 4.84 & 3.39 & 3.68 & 3.29 & 3.11 & 1.79 & 0.72 & 0.84 & 1.17 & 0.91 & 0.79 & 0.54 & 0.50 \\
2.50 & 4.43 & 3.43 & 4.60 & 3.64 & 3.49 & 2.10 & 0.67 & 0.67 & 1.25 & 0.98 & 0.94 & 0.61 & 0.64 \\
5.00 & 3.11 & 3.65 & 7.86 & 4.85 & 4.76 & 3.34 & 0.76 & 0.16 & 1.90 & 1.23 & 1.54 & 0.29 & 1.38 \\
7.50 & 2.34 & 4.00 & 11.01 & 6.00 & 5.89 & 4.59 & 1.03 & 0.61 & 2.84 & 1.40 & 2.05 & 0.97 & 2.00 \\
\hline
\end{tabular}

Table 8. List of measured selected RMS values of harmonics $I_{h}$ in relation to the basic harmonics for LED2.

\begin{tabular}{cccccccccccccc}
\hline $\begin{array}{c}\mathbf{T H D}_{\boldsymbol{V}} \\
\mathbf{( \% )}\end{array}$ & $\begin{array}{c}\boldsymbol{I}_{\mathbf{3}} \\
\mathbf{( \% )}\end{array}$ & $\begin{array}{c}\boldsymbol{I}_{\mathbf{5}} \\
\mathbf{( \% )}\end{array}$ & $\begin{array}{c}\boldsymbol{I}_{\mathbf{7}} \\
\mathbf{( \% )}\end{array}$ & $\begin{array}{c}\boldsymbol{I}_{\mathbf{9}} \\
\mathbf{( \% )}\end{array}$ & $\begin{array}{c}\boldsymbol{I}_{\mathbf{1 1}} \\
\mathbf{( \% )}\end{array}$ & $\begin{array}{c}\boldsymbol{I}_{\mathbf{1 3}} \\
\mathbf{( \% )}\end{array}$ & $\begin{array}{c}\boldsymbol{I}_{\mathbf{1 5}} \\
\mathbf{( \% )}\end{array}$ & $\begin{array}{c}\boldsymbol{I}_{\mathbf{1 7}} \\
\mathbf{( \% )}\end{array}$ & $\begin{array}{c}\boldsymbol{I}_{\mathbf{1 9}} \\
\mathbf{( \% )}\end{array}$ & $\begin{array}{c}\boldsymbol{I}_{\mathbf{2 1}} \\
\mathbf{( \% )}\end{array}$ & $\begin{array}{c}\boldsymbol{I}_{\mathbf{2 3}} \\
\mathbf{( \% )}\end{array}$ & $\begin{array}{c}\boldsymbol{I}_{\mathbf{2 5}} \\
\mathbf{( \% )}\end{array}$ & $\begin{array}{c}\boldsymbol{I}_{\mathbf{2 7}} \\
\mathbf{( \% )}\end{array}$ \\
\hline 0 & 14.48 & 6.52 & 3.29 & 1.89 & 1.16 & 0.74 & 0.52 & 0.40 & 0.33 & 0.26 & 0.25 & 0.24 & 0.22 \\
1.79 & 13.88 & 6.20 & 5.65 & 2.64 & 1.12 & 0.69 & 0.31 & 0.44 & 1.13 & 0.59 & 0.79 & 0.42 & 0.44 \\
2.50 & 13.82 & 6.09 & 6.60 & 3.08 & 1.48 & 1.23 & 0.45 & 0.51 & 1.48 & 0.74 & 1.04 & 0.55 & 0.65 \\
5.00 & 13.05 & 5.72 & 10.05 & 4.84 & 3.08 & 3.18 & 1.15 & 0.91 & 2.83 & 1.24 & 1.89 & 0.21 & 1.47 \\
7.50 & 12.39 & 5.46 & 13.46 & 6.72 & 4.81 & 5.10 & 1.91 & 1.38 & 4.12 & 1.67 & 2.70 & 1.29 & 2.29 \\
\hline
\end{tabular}

\subsection{Studies of the Influence of the Level of Dimming}

One of the factors influencing the shape of the supply current, and thus the electrical parameters of the existing luminaires, is the light control system. Such control systems are used increasingly, mainly to improve the functionality and energy efficiency of lighting installations. Adaptable for 
work in control systems, lighting luminaires are equipped with electronic power supplies with control inputs. The control inputs are made as analogue operating in the $1 \mathrm{~V}-10 \mathrm{~V}$ or digital DALI (Digital Addressable Lighting Interface) standard.

In order to verify the impact of the level of control on the level of generated disturbances to the power supply network for laboratory tests, two lighting luminaires made in LED technology were selected. The control of the luminaire marked as LED3 was carried out using a dedicated computer program using communication in the DALI system. The program has assigned percent control values which, as shown by the measurements, do not correspond to the same percentage of active power and luminous flux of the luminaire. The table contains percent control levels consistent with the notation adopted by the manufacturer. The LED4 luminaire power supply is equipped with an analogue control input made in the 1-10 V standard. The control was implemented by providing a control voltage to this input from a DC stabilized power supply. During the measurements, both luminaires were supplied with non-deformed voltage.

The registered electrical parameters of the tested LED3 luminaire, depending on the level of control, are included in Table 9.

Table 9. Summary of measured values of electrical parameters of the LED3 luminaire.

\begin{tabular}{|c|c|c|c|c|c|c|c|c|c|c|c|c|}
\hline Dimming & $\begin{array}{c}I \\
(\mathrm{~mA})\end{array}$ & $\begin{array}{c}I_{1} \\
(\mathrm{~mA})\end{array}$ & $\begin{array}{c}I_{H} \\
(\mathbf{m A})\end{array}$ & $\begin{array}{c}T H D_{I} \\
(\%)\end{array}$ & $\begin{array}{c}P \\
(W)\end{array}$ & $\begin{array}{c}S \\
\text { (VA) }\end{array}$ & $\begin{array}{c}S_{1} \\
\text { (VA) }\end{array}$ & $\begin{array}{c}D_{I} \\
\text { (var) }\end{array}$ & $\begin{array}{c}Q \\
\text { (var) }\end{array}$ & $\cos \varphi$ & $P F$ & $\tan \varphi$ \\
\hline $10 \%$ & 215.85 & 211.04 & 45.31 & 21.05 & 37.705 & 49.69 & 48.59 & 10.43 & 30.64 & 0.776 & 0.759 & 0.813 \\
\hline $20 \%$ & 261.90 & 258.21 & 43.81 & 16.84 & 49.617 & 60.29 & 59.44 & 10.09 & 32.73 & 0.835 & 0.823 & 0.660 \\
\hline $30 \%$ & 325.84 & 322.50 & 46.53 & 14.34 & 65.332 & 75.01 & 74.24 & 10.71 & 35.25 & 0.880 & 0.871 & 0.539 \\
\hline $40 \%$ & 381.03 & 378.11 & 47.08 & 12.34 & 79.265 & 87.71 & 87.04 & 10.84 & 35.95 & 0.911 & 0.904 & 0.454 \\
\hline $50 \%$ & 434.45 & 431.79 & 48.00 & 11.01 & 91.87 & 100.00 & 99.39 & 11.05 & 37.91 & 0.924 & 0.919 & 0.413 \\
\hline $60 \%$ & 484.25 & 481.61 & 50.50 & 10.42 & 103.5 & 111.47 & 110.86 & 11.62 & 39.72 & 0.934 & 0.929 & 0.384 \\
\hline $70 \%$ & 529.60 & 527.03 & 52.11 & 9.82 & 114.22 & 121.89 & 121.30 & 11.99 & 40.81 & 0.942 & 0.937 & 0.357 \\
\hline $80 \%$ & 571.34 & 568.94 & 52.31 & 9.15 & 124.22 & 131.48 & 130.93 & 12.04 & 41.37 & 0.949 & 0.945 & 0.333 \\
\hline $90 \%$ & 610.45 & 608.25 & 51.78 & 8.45 & 133.56 & 140.48 & 139.97 & 11.92 & 41.86 & 0.954 & 0.951 & 0.313 \\
\hline $100 \%$ & 648.47 & 646.38 & 52.02 & 8.00 & 142.49 & 149.21 & 148.73 & 11.97 & 42.61 & 0.958 & 0.955 & 0.299 \\
\hline
\end{tabular}

The change in the level of the LED3 dimming level obviously affects the active power level and, consequently, the RMS value of the supply current. These dependencies are practically linear. In the case of analysing changes in reactive power, this decrease is also linear, but the range of changes is smaller than for active power. For the change in the level of control from $10 \%$ to $100 \%$, the active power increases in the range from $37.71 \mathrm{~W}$ to $142.49 \mathrm{~W}$. With the same range of changes in the level of control, reactive power increases from 30.64 var to 42.61 var (about 39\%). Behaviour in this case, apparent power is a resultant of changes in active and reactive power. During adjustment, the power factor $\cos \varphi$ of the luminaire is not kept at the same level. For full control it is 0.96 , but for $10 \%$ control it drops to 0.78 . In the point of view of the impact of the electricity receiver, which is the luminaire on the power supply network, the most undesirable phenomenon is the increase in the $T H D_{I}$. During the change of the level of control from full power to $10 \%$, its value increases from $8 \%$ to $21 \%$. Waveforms of currents and voltages with $10 \%$ and $100 \%$ level of control are shown in Figure 9.

Percentage RMS values of individual harmonics depending on the level of control are presented in Table 10. Reducing the level of the control causes an increase in the percentage share of harmonics related to the basic harmonics. It is the largest for harmonics on the order of 3, 5, 7 and 9, respectively. For the harmonics on the order of 3 , the change of the level from full power to $10 \%$ increases its relative value from $6 \%$ to $15 \%$. In the case of harmonics of the order of 5 , this change ranges from $3 \%$ to $10 \%$.

An analogous analysis was made for the luminaire marked LED4. The registered electrical parameters of this luminaire as a function of the control voltage $U_{C}$ are included in Table 11. 


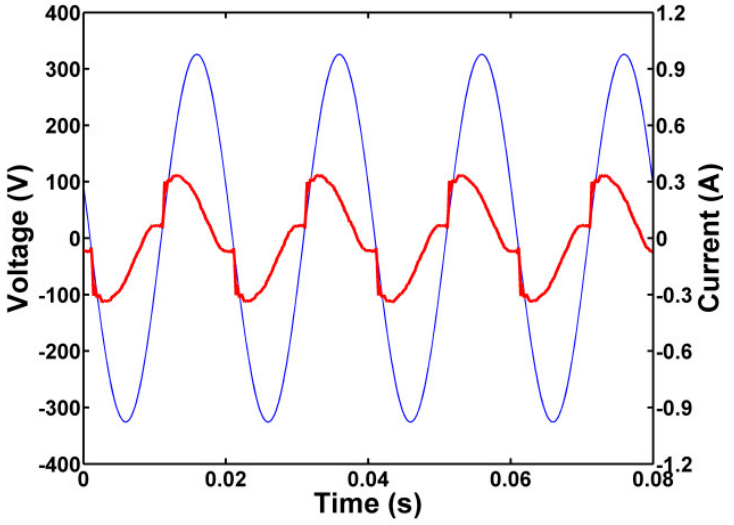

(a)

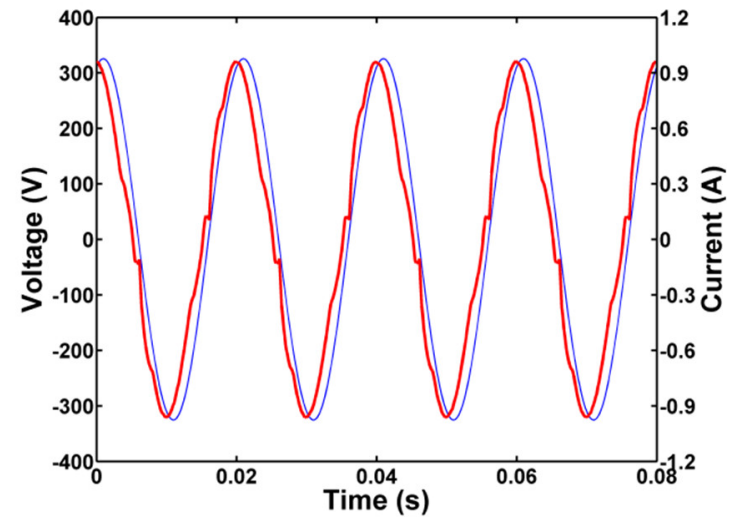

(b)

Figure 9. Waveforms of voltage and current for luminaire marked as LED3 for: (a) $10 \%$ dimming level and (b) $100 \%$ dimming level.

Table 10. List of measured selected RMS values of harmonics $I_{h}$ in relation to the basic harmonics for LED3

\begin{tabular}{cccccccccccccc}
\hline Dimming & $\begin{array}{c}\boldsymbol{I}_{\mathbf{3}} \\
\mathbf{( \% )}\end{array}$ & $\begin{array}{c}\boldsymbol{I}_{\mathbf{5}} \\
\mathbf{( \% )}\end{array}$ & $\begin{array}{c}\boldsymbol{I}_{\mathbf{7}} \\
\mathbf{( \% )}\end{array}$ & $\begin{array}{c}\boldsymbol{I}_{\mathbf{9}} \\
\mathbf{( \% )}\end{array}$ & $\begin{array}{c}\boldsymbol{I}_{\mathbf{1 1}} \\
\mathbf{( \% )}\end{array}$ & $\begin{array}{c}\boldsymbol{I}_{\mathbf{1 3}} \\
\mathbf{( \% )}\end{array}$ & $\begin{array}{c}\boldsymbol{I}_{\mathbf{1 5}} \\
\mathbf{( \% )}\end{array}$ & $\begin{array}{c}\boldsymbol{I}_{\mathbf{1 7}} \\
\mathbf{( \% )}\end{array}$ & $\begin{array}{c}\boldsymbol{I}_{\mathbf{1 9}} \\
\mathbf{( \% )}\end{array}$ & $\begin{array}{c}\boldsymbol{I}_{\mathbf{2 1}} \\
\mathbf{( \% )}\end{array}$ & $\begin{array}{c}\boldsymbol{I}_{\mathbf{2}} \\
\mathbf{( \% )}\end{array}$ & $\begin{array}{c}\boldsymbol{I}_{\mathbf{2 5}} \\
\mathbf{( \% )}\end{array}$ & $\begin{array}{c}\boldsymbol{I}_{\mathbf{2}} \\
\mathbf{( \% )}\end{array}$ \\
\hline $10 \%$ & 14.56 & 9.91 & 6.79 & 4.49 & 3.54 & 3.42 & 2.54 & 2.39 & 2.11 & 1.71 & 1.33 & 1.28 & 1.30 \\
$20 \%$ & 11.13 & 6.81 & 5.59 & 4.92 & 3.73 & 2.22 & 1.97 & 2.05 & 2.00 & 2.05 & 1.91 & 1.72 & 1.82 \\
$30 \%$ & 9.77 & 5.93 & 4.23 & 2.94 & 2.57 & 3.17 & 2.89 & 2.20 & 2.08 & 1.71 & 1.53 & 1.80 & 1.61 \\
$40 \%$ & 8.44 & 4.65 & 3.21 & 3.36 & 3.34 & 2.39 & 2.04 & 2.31 & 1.53 & 1.70 & 1.75 & 1.29 & 0.88 \\
$50 \%$ & 7.06 & 4.84 & 3.41 & 2.95 & 2.76 & 2.55 & 1.25 & 1.59 & 2.11 & 1.49 & 1.03 & 0.91 & 0.52 \\
$60 \%$ & 6.60 & 5.18 & 3.56 & 2.38 & 1.43 & 2.26 & 2.17 & 1.38 & 1.37 & 1.40 & 0.84 & 0.47 & 0.54 \\
$70 \%$ & 6.33 & 5.08 & 3.21 & 2.32 & 1.01 & 1.51 & 2.25 & 1.59 & 0.89 & 0.95 & 1.03 & 0.60 & 0.31 \\
$80 \%$ & 6.02 & 4.64 & 2.58 & 2.60 & 1.42 & 1.05 & 1.66 & 1.79 & 1.06 & 0.65 & 0.73 & 0.67 & 0.36 \\
$90 \%$ & 5.85 & 3.91 & 1.81 & 2.55 & 2.00 & 1.08 & 1.12 & 1.53 & 1.31 & 0.68 & 0.45 & 0.49 & 0.45 \\
$100 \%$ & 5.93 & 3.13 & 1.33 & 2.19 & 2.32 & 1.38 & 0.87 & 1.07 & 1.18 & 0.84 & 0.48 & 0.38 & 0.40 \\
\hline
\end{tabular}

Table 11. Summary of measured values of electrical parameters of the LED4 luminaire.

\begin{tabular}{ccccccccccccc}
\hline $\begin{array}{c}\boldsymbol{U}_{\boldsymbol{C}} \\
(\mathbf{V})\end{array}$ & $\begin{array}{c}\boldsymbol{I} \\
(\mathbf{m A})\end{array}$ & $\begin{array}{c}\boldsymbol{I}_{\mathbf{1}} \\
(\mathbf{m A})\end{array}$ & $\begin{array}{c}\boldsymbol{I}_{\boldsymbol{H}} \\
(\mathbf{m A})\end{array}$ & $\begin{array}{c}\mathbf{T H D}_{\boldsymbol{I}} \\
(\mathbf{\%})\end{array}$ & $\begin{array}{c}\boldsymbol{P} \\
(\mathbf{W})\end{array}$ & $\begin{array}{c}\boldsymbol{S} \\
(\mathbf{V A})\end{array}$ & $\begin{array}{c}\boldsymbol{S}_{\mathbf{1}} \\
(\mathbf{V A})\end{array}$ & $\begin{array}{c}\boldsymbol{D}_{\mathbf{I}} \\
(\mathbf{v a r})\end{array}$ & $\begin{array}{c}\boldsymbol{Q} \\
(\mathbf{v a r})\end{array}$ & $\boldsymbol{c o s} \boldsymbol{\varphi}$ & $\boldsymbol{P F}$ & $\tan \boldsymbol{\varphi}$ \\
\hline 1 & 73.21 & 59.69 & 42.38 & 38.01 & 6.28 & 16.84 & 12.25 & 8.69 & 14.03 & 0.408 & 0.373 & 2.235 \\
2 & 81.43 & 76.17 & 28.79 & 36.87 & 9.05 & 18.73 & 17.52 & 6.62 & 15.00 & 0.516 & 0.483 & 1.658 \\
3 & 83.57 & 81.47 & 18.60 & 22.20 & 12.85 & 19.22 & 18.74 & 4.28 & 13.64 & 0.686 & 0.668 & 1.062 \\
4 & 94.21 & 93.09 & 14.44 & 15.13 & 16.62 & 21.67 & 21.41 & 3.32 & 13.50 & 0.776 & 0.767 & 0.812 \\
5 & 109.31 & 108.05 & 16.55 & 15.01 & 20.68 & 25.14 & 24.85 & 3.81 & 13.79 & 0.832 & 0.822 & 0.667 \\
6 & 124.25 & 122.86 & 18.53 & 14.90 & 24.48 & 28.58 & 28.26 & 4.26 & 14.11 & 0.866 & 0.857 & 0.576 \\
7 & 139.92 & 138.45 & 20.23 & 14.43 & 28.36 & 32.18 & 31.84 & 4.65 & 14.48 & 0.891 & 0.881 & 0.511 \\
8 & 156.79 & 155.28 & 21.71 & 13.85 & 32.51 & 36.06 & 35.71 & 4.99 & 14.78 & 0.910 & 0.902 & 0.455 \\
9 & 156.73 & 155.21 & 21.77 & 13.89 & 32.48 & 36.04 & 35.69 & 5.01 & 14.79 & 0.910 & 0.901 & 0.455 \\
10 & 156.73 & 155.21 & 21.77 & 13.91 & 32.48 & 36.04 & 35.69 & 5.01 & 14.79 & 0.910 & 0.901 & 0.455 \\
\hline
\end{tabular}

Similar to LED3, the control level adjustment affects the active power and the RMS value of the supply current. For these parameters, this relationship is linear for the analysed range. It can be observed that in the range of control voltages from $8 \mathrm{~V}$ to $10 \mathrm{~V}$, the luminaire is controlled at $100 \%$. The adjustment range is, therefore, in the range from $1 \mathrm{~V}$ to $8 \mathrm{~V}\left(U_{C}\right)$. In contrast to active power, reactive power in the entire regulation range does not change noticeably, which in the case of changes in active power must result in a reduction in the power factor. Depending on whether it is defined as $\cos \varphi$ or $P F$, its value decreases from 0.91 to 0.41 for $\cos \varphi$ and from 0.9 to 0.37 for $P F$, respectively. The differences occurring here result from taking into account in $P F$ the level of voltage and current deformation. The change in the level of control clearly has a negative effect on the $T H D_{I}$ value. In the range of changing the power of the luminaire from $10 \mathrm{~V}$ to $1 \mathrm{~V}$, it varies from $13.91 \%$ to $38.01 \%$. 
Such a significant increase of the $T H D_{I}$ coefficient, is a consequence of the increase in the deformation of the supply current for the control at $U_{C}=1 \mathrm{~V}$ in relation to the shape of this current for full power $\left(U_{C}=10 \mathrm{~V}\right)$ (Figure 10).

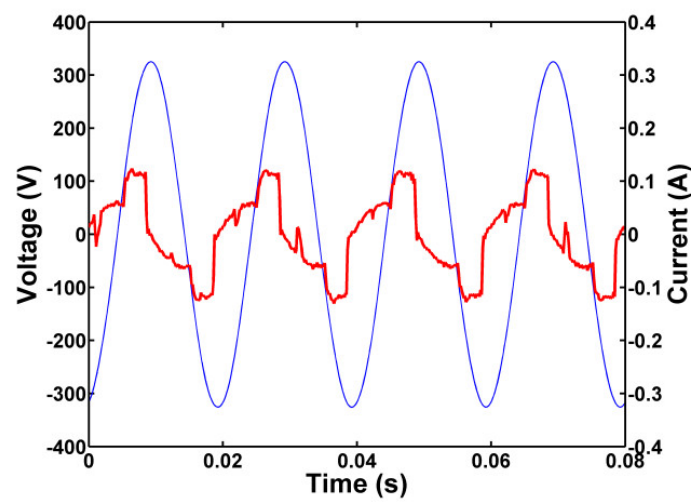

(a)

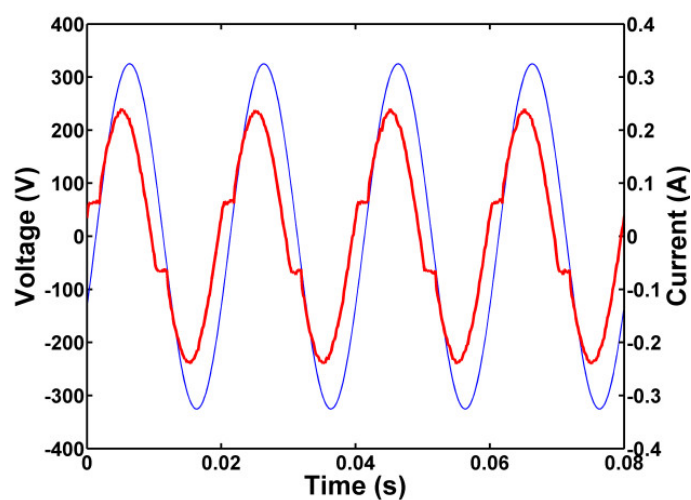

(b)

Figure 10. Waveforms of voltage and current for luminaire marked as LED4 for: (a) $U_{C}=1 \mathrm{~V}$ and (b) $U_{C}=10 \mathrm{~V}$.

Percentage RMS values of individual harmonics depending on the level of control are presented in Table 12. Reducing the level of the control causes an increase in the percentage share of harmonics related to the basic harmonics. For the 3rd order harmonic, the change in the level of control from $U_{C}=10 \mathrm{~V}$ to $U_{C}=1 \mathrm{~V}$ increases its relative value from $11.92 \%$ to $30.57 \%$.

Table 12. List of measured selected RMS values of harmonics $I_{h}$ in relation to the basic harmonics for LED4.

\begin{tabular}{|c|c|c|c|c|c|c|c|c|c|c|c|c|c|}
\hline $\begin{array}{l}U_{C} \\
(\mathrm{~V})\end{array}$ & $\begin{array}{c}I_{3} \\
(\%)\end{array}$ & $\begin{array}{c}I_{5} \\
(\%)\end{array}$ & $\begin{array}{c}I_{7} \\
(\%)\end{array}$ & $\begin{array}{c}I_{9} \\
(\%)\end{array}$ & $\begin{array}{l}I_{11} \\
(\%)\end{array}$ & $\begin{array}{l}I_{13} \\
(\%)\end{array}$ & $\begin{array}{l}I_{15} \\
(\%)\end{array}$ & $\begin{array}{l}I_{17} \\
(\%)\end{array}$ & $\begin{array}{l}I_{19} \\
(\%)\end{array}$ & $\begin{array}{l}I_{21} \\
(\%)\end{array}$ & $\begin{array}{l}I_{23} \\
(\%)\end{array}$ & $\begin{array}{l}I_{25} \\
(\%)\end{array}$ & $\begin{array}{l}I_{27} \\
(\%)\end{array}$ \\
\hline 1 & 30.57 & 14.66 & 4.77 & 7.50 & 5.89 & 2.12 & 3.84 & 2.01 & 1.34 & 2.85 & 1.83 & 0.98 & 1.59 \\
\hline 2 & 32.34 & 5.83 & 12.71 & 4.61 & 5.53 & 4.38 & 3.38 & 3.15 & 2.18 & 3.21 & 1.12 & 2.35 & 1.32 \\
\hline 3 & 18.66 & 10.57 & 2.01 & 5.08 & 2.51 & 1.37 & 1.89 & 1.23 & 1.15 & 1.67 & 0.76 & 1.11 & 0.73 \\
\hline 4 & 10.03 & 9.61 & 5.08 & 1.40 & 1.17 & 1.45 & 1.34 & 1.16 & 0.66 & 0.76 & 0.70 & 0.73 & 0.61 \\
\hline 5 & 11.76 & 7.68 & 4.27 & 1.81 & 0.58 & 0.96 & 1.28 & 1.06 & 0.67 & 0.47 & 0.50 & 0.61 & 0.62 \\
\hline 6 & 12.34 & 6.67 & 4.08 & 1.90 & 0.69 & 0.65 & 0.97 & 0.95 & 0.68 & 0.47 & 0.29 & 0.44 & 0.60 \\
\hline 7 & 12.14 & 6.17 & 3.77 & 1.99 & 0.88 & 0.52 & 0.58 & 0.71 & 0.72 & 0.63 & 0.33 & 0.32 & 0.40 \\
\hline 8 & 11.88 & 5.55 & 3.57 & 2.18 & 1.04 & 0.35 & 0.35 & 0.58 & 0.66 & 0.59 & 0.43 & 0.29 & 0.28 \\
\hline 9 & 11.91 & 5.54 & 3.54 & 2.18 & 1.07 & 0.34 & 0.33 & 0.56 & 0.65 & 0.58 & 0.43 & 0.29 & 0.27 \\
\hline 10 & 11.92 & 5.52 & 3.54 & 2.17 & 1.05 & 0.34 & 0.34 & 0.56 & 0.65 & 0.58 & 0.43 & 0.29 & 0.27 \\
\hline
\end{tabular}

\section{Discussion}

The development of LED technology in road lighting has increased their use. The luminaire made in LED technology consists of LED matrix, power supply and, optionally, control systems. Control systems can be integrated with the power supply or be a separate device. The power supplies used in LED luminaires are switched-mode power supplies (SMPS). They are usually designed for the nominal power load and voltage supply with specified parameters, e.g., for a given range of the RMS voltage value. In the case of power supplies enabling power reduction they can work even at $10 \%$ load. As the active power decreases, the level of the input current deformation to the supply network increases, even several times. Due to the decrease in the power of the receiver, which is the luminaire, its negative effect does not increase proportionally with the increase in the value of the $T H D_{I}$ coefficient. Although manufacturers prove that with the reduction of power, the harmonic values of the current will not exceed the limit values specified in the EN 61000-3-2 standard [20], this may cause negative phenomena, e.g., increase the risk of resonance. 
The electrical parameters of tested luminaires were measured for the RMS value of the supply voltage in the range of $230 \mathrm{~V} \pm 10 \%$. Based on the results of the measurements, the values of distorted voltage and currents and power were calculated in accordance with the standard [25]. Based on the analysis, it can be concluded that the change in the RMS value of the supply voltage has the greatest impact on the $Q$ reactive power value. The change of reactive power affects the value of the $\tan \varphi$. factor. The problem of reactive power in road lighting installations is not adequately analysed. In many countries, different methods are used to calculate costs for reactive power consumption. Some of them do not bear the cost of reactive energy. In other countries, only the sub-contracted consumption of reactive power is considered. These fees are calculated after exceeding the given value of the power factor $\cos \varphi$ or $\tan \varphi$. In some, reactive energy consumption is always subject to fees.

The RMS value of the supply voltage in real power grids is very often different from the rated value. That is why, what has been proven in this article, the electrical parameters of LED luminaires are subject to change, which may be the reason for differences in electricity charges (in particular reactive energy) between the adopted assumptions and real values. In the actual power grid, the supply voltage is practically always deformed. The luminaire is then supplied with distorted voltage. EMC tests in accordance with the standard [20] are performed when the power supply is practically sinusoidal. It is important from the operational point of view to determine the impact of voltage supply deformation on the electrical parameters of road-lighting luminaires. For a low voltage network in accordance with the standard [20], the permissible $T H D_{V}$ voltage value is $8 \%$, i.e., a large content of higher harmonics is allowed.

Two LED luminaires were tested for the effect of the voltage deformation. The level of deformation of the supply voltage fed to the input terminals of the lighting luminaires by the generator was expressed by changing the value of the deformation coefficient $T H D_{V}$ with the higher harmonics of the supply voltage. The assumed scope of its changes resulted from the assumption of moving in this case in the range of limit values given in the applicable regulations [10]. The increase in the voltage deformation level of the supply voltage within the accepted limits causes, for the LED1 luminaire, an increase in the $T H D_{I}$ value by more than $97 \%$ and in the case of LED 2 by $36 \%$. Possible consequences of this phenomenon will be, among others, an increase in energy losses in components of the power supply network. For cables, this will increase the current in the neutral conductor and the skin effect, additional hysteresis and eddy current losses that may appear in the supply transformer. It can be concluded that for tested LED luminaires, the deformation on the supply voltage affects the spectrum of higher harmonics of the luminaires current. No significant influence was observed on other electrical parameters.

Actions aimed at improving the energy efficiency of road lighting installations cause the increasingly common use of controlled LED luminaires. They can work, for example, according to the assumed lighting schedule. In the hours of reduced traffic in accordance with the relevant standards [1], the lighting class of the road can be lowered, which is equivalent to a reduction in the power of luminaires. In order to accurately determine energy efficiency and the analysis of the impact of luminaires on the power supply network is knowledge of their control characteristics. The control characteristics should be determined for all required electrical and photometric parameters. Such characteristics have been determined for two LED luminaires equipped with various control systems.

Changes in the active power of both tested luminaires are practically proportional to the dimming. Other parameters, except $T H D_{I}$ also depend linearly on the level of control, although the proportionality factors are different for different parameters. The greatest dependence on the level of the control was observed for the $T H D_{I}$ coefficient, which value increased with the power reduction almost 3 times. The construction of the power supply changes the reactive power does not occur to such an extent as to change the active power. The consequence of this phenomenon is the decrease in the power factor when regulating power down, and in particular defined as $P F, \operatorname{not} \cos \varphi$. This may be affected by the value of reactive energy costs. 


\section{Conclusions}

The main purpose of the article was to present the influence of power supply voltage parameters and control on the electrical parameters of road luminaires. All tested luminaires are non-linear receivers that generate current harmonics to the supply network. The level of generated disturbances depends primarily on the design of the power supply, e.g., on the type of PFC system. It was found that all tested luminaires are capacitive receivers.

The rapid development of power supplies used in road luminaires makes it very difficult to generalize results. Each power supply can have a different control algorithm and construction. Therefore, it should be tested and analysed individually.

Author Contributions: Conceptualization, R.S., P.M.; Data curation, R.S. and P.M.; Formal analysis, R.S. and P.M.; Methodology, R.S. and P.M.; Writing—original draft, R.S. and P.M.; Writing—review and editing, R.S. and P.M.

Funding: This research received no external funding.

Conflicts of Interest: The authors declare no conflict of interest.

\section{List of Fundamental Variables}

$V \quad$ RMS values of voltage, $(\mathrm{V})$

I RMS values of current, (A)

$V_{0} \quad$ constant component of voltage, (V)

$I_{0} \quad$ constant component of current, (A)

$V_{1} \quad$ value of the fundamental voltage harmonic, $(\mathrm{V})$

$I_{1} \quad$ value of the fundamental current harmonic, (A)

$P \quad$ active power of receiver, $(\mathrm{W})$

$P_{1} \quad$ active power of receiver associated with the voltage and current of the fundamental harmonic, $(\mathrm{W})$

$P_{H} \quad$ active power of receiver associated with harmonics of the order different from unity, (W)

$Q \quad$ reactive power, (var)

$Q_{1} \quad$ reactive power for the fundamental harmonic, (var)

$P F \quad$ power factor

$P F_{1} \quad$ power factor for the fundamental harmonic

$T H D_{\text {I }} \quad$ current total harmonic distortion factor, $(\%)$

$T H D_{V}$ voltage total harmonic distortion factor, (\%)

$\operatorname{tg} \varphi \quad$ tangent $\varphi$

$S \quad$ apparent power, (VA)

$S_{H} \quad$ harmonic apparent power, (VA)

$S_{1} \quad$ apparent power of the fundamental harmonic, (VA)

$D$ deformation power, (var)

$D_{I} \quad$ current distortion power, (var)

$D_{V} \quad$ voltage distortion power, (var)

\section{References}

1. EN 13201:2016—Road Lighting; European Union: Brussels, Belgium, 2016.

2. Azcarate, I.; Gutierrez, J.J.; Lazkano, A.; Saiz, P.; Redondo, K.; Leturiondo, L.A. Experimental study of the response of efficient lighting technologies to complex voltage fluctuations. Electr. Power Energy Syst. 2014, 63, 499-506. [CrossRef]

3. Bollen, M.H.J.; Rönnberg, S.K.; Larsson, E.O.A.; Wahlberg, M.; Lundmark, C.M. Harmonic Emission from Installations with Energy-Efficient Lighting. In Proceedings of the 11th International Conference on Electrical Power Quality and Utilisation, Lisbon, Portugal, 17-19 October 2011; pp. 1-6.

4. Dolara, A.; Faranda, R.; Guzzetti, S.; Leva, S. Power Quality in Public Lighting Systems. In Proceedings of the 14th International Conference on Harmonics and Quality of Power, Bergamo, Italy, 26-29 September 2010; pp. 1-7. 
5. Gil de Castro, A.; Moreno, M.A.; Pallarés, L.V.; Pérez, A.A. Harmonic Effect in Street Lighting. In Proceedings of the 7th International Conference-Workshop Compatibility and Power Electronics (CPE), Tallinn, Estonia, 1-3 June 2011; pp. 16-21.

6. Gil-de-Castro, A.; Rönnberg, S.K.; Bollen, M.H.J.; Moreno-Muñoz, A. Study on harmonic emission of domestic equipment combined with different types of lighting. Electr. Power Energy Syst. 2014, 55, 116-127. [CrossRef]

7. Kalaira, A.; Abasb, N.; Kalairc, A.R.; Saleemd, Z.; Khana, N. Review of harmonic analysis, modeling and mitigation techniques. Renew. Sustain. Energy Rev. 2017, 78, 1152-1187. [CrossRef]

8. Pabjanczyk, W.; Sikora, R.; Markiewicz, P.; Gabryjelski, Z. Influence of LED luminaires on supply network. Prz. Elektrotech. 2010, 86, 229-232.

9. Pabjanczyk, W.; Sikora, R.; Markiewicz, P.; Gabryjelski, Z. The influence of a road LED luminaires on the electrical power quality in a power networks. Prz. Elektrotech. 2011, 87, 120-123.

10. Rios, S.; Castaiieda, R.; Veas, D. Harmonic distortion and power factor assessment in city street gas discharge lamps. IEEE Trans. Power Deliv. 1996, 11, 1013-1020. [CrossRef]

11. Rönnberg, S.K.; Wahlberg, M.; Bollen, M.H.J. Harmonic Emission before and after changing to LED and CFL-Part II: Field Measurements for a Hotel. In Proceedings of the Proceedings of 14th International Conference on Harmonics and Quality of Power, Bergamo, Italy, 26-29 September 2010; pp. 1-6.

12. Sikora, R.; Markiewicz, P. The influence of modern luminaires on the supply network. Prz. Elektrotech. 2010, $86,61-64$.

13. EN 50160:2007 Voltage Characteristics of Electricity Supplied by Public Distribution Systems; European Union: Brussels, Belgium, 2007.

14. EN 50464-3:2007 Three-Phase Oil-Immersed Distribution Transformers $50 \mathrm{~Hz}$, from $50 \mathrm{kVA}$ to $2500 \mathrm{kVA}$ with Highest Voltage for Equipment not Exceeding $36 \mathrm{kV}$. Determination of the Power Rating of a Transformer Loaded with Non-Sinusoidal Currents; European Union: Brussels, Belgium, 2007.

15. Yong, J.; Xu, W. Method to Estimate the Impact of Harmonic and Unbalanced Currents on the Ampacity of Concentric Neutral Cables. IEEE Trans. Power Deliv. 2016, 31, 1971-1979. [CrossRef]

16. Shagerdmootaab, A.; Moallem, M. Filter Capacitor Minimization in a Flyback LED Driver Considering Input Current Harmonics. IEEE Trans. Power Electron. 2015, 30, 4467-4476. [CrossRef]

17. Sainz, L.; Balcells, J. Harmonic Interaction Influence Due to Current Source Shunt Filters in Networks Supplying Nonlinear Loads. IEEE Trans. Power Deliv. 2012, 27, 1385-1393. [CrossRef]

18. Rönnberg, S.; Bollen, M.H.J. Power quality issues in the electric power system of the future. Electr. J. 2016, 29, 49-61. [CrossRef]

19. Rönnberg, S.K.; Wahlberg, M.; Bollen, H.J.M. Harmonic Emission before and after Changing to LED and CFL -Part I: Laboratory measurements for a domestic customer. In Proceedings of the 14th International Conference on Harmonics and Quality of Power, Bergamo, Italy, 26-29 September 2010; pp. 1-7.

20. EN 61000-3-2:2007 Electromagnetic Compatibility (EMC)_Part 3-2: Limits—Limits for Harmonic Current Emissions (Equipment Input Current <= 16 A per Phase); European Union: Brussels, Belgium, 2007.

21. Acarkan, B.; Zorlu, S.; Kili, O. Nonlinear Resistance Modeling using MATLAB and Simulink in Estimation of City Street Lighting Harmonic Activity. In Proceedings of the International Conference on Computer as a Tool, Belgrade, Serbia, 21-24 November 2005; Volume 2, pp. 1251-1254.

22. Lamich, M.; Balcells, J.; Corbal'an, M.; Griful, E. Nonlinear Loads Model for Harmonics Flow Prediction, Using Multivariate Regression. IEEE Trans. Ind. Electron. 2017, 64, 4820-4827. [CrossRef]

23. Wang, W.; Zhu, G.D.; Xu, D.G. A Physics-Based Model for HID Lamps with Rectifying Effect. In Proceedings of the IEEE Vehicle Power and Propulsion Conference (VPPC), Harbin, China, 3-5 September 2008; pp. 1-5.

24. Guan, X.; Li, Z. A HID Lamp Model in Simulink Based on the Principle of Electric Arc. In Communication Systems and Information Technology; Lecture Notes in Electrical Engineering; Springer: Berlin/Heidelberg, Germany, 2011; Volume 100, pp. 235-242.

25. IEEE Std. 1459-2010. Definitions for the Measurement of Electric Power Quantities under Sinusoidal, Nonsunusoidal, Balanced, or Unbalanced Conditions; IEEE: Piscataway, NJ, USA, 2010.

(C) 2019 by the authors. Licensee MDPI, Basel, Switzerland. This article is an open access article distributed under the terms and conditions of the Creative Commons Attribution (CC BY) license (http:/ / creativecommons.org/licenses/by/4.0/). 